\title{
Multi Epitope Vaccine Prediction Against Aichi Virus using Immunoinformatic Approach
}

Asma Ali Hassan Ali 1,2, Sahar Abdeen Abdalla Mohamed 1, Marwa Abdulrahman Omer Musa 1,4, Amani Faisal Bushra ELtahier 1,3, Walaa Mohammed Alsamani Abdelrahman Ali 1,5, Elaf Ahmed Mohammed Ali Ibrahim ${ }^{1}$, Ahmed Hamdi', Mohamed A. Hassan ${ }^{1,6}$.

1. Department of bioinformatics, Africa city of technology, Khartoum, Sudan.

2. Faculty of science, University of Khartoum, Khartoum, Sudan.

3. Faculty of medical laboratory science, Riyadh international college, Khartoum, Sudan.

4. Alshifa hospital, Khartoum, Sudan.

5. UMbada maternal and child health hospital, Khartoum, Sudan.

6. Department of Bioinformatics, DETAGEN Genetic Diagnostics Center, Kayseri, Turkey

Corresponding author: Asma Ali Hassan Ali

\section{Asma.alihn@gmail.com}




\begin{abstract}
Aichi virus, AiV is single stranded negative sense RNA genome belonging to the genus Kobuviru, a family of Picornaviridae that causes severe gastroenteritis. There is no treatment or vaccine for it, thus the aim of this study is to design a peptide vaccine using immunoinformatic approaches to analyze the viral Protein VP1 of AiV-1 strain, to determine the conserved region which is further studied to predict all possible epitopes that can be used as a peptide vaccine. A total of 38 Aichi virus VP1 retrieved from NCBI database were aligned to determine the conservancy and to predict the epitopes using IEDB analysis resource. Three epitopes predicted as a peptide vaccine for B cell was (PLPPDT, PPLPTP, and LPPLPTP). For T cell, two epitopes showed high affinity to MHC class I (FSIPYTSPL and TMVSFSIPY) and high coverage against the whole world population. Also, in MHC class II, three epitopes that interact with most frequent MHC class II alleles (FTYIAADLR and YMAEVPVSA) with high coverage in the whole world population. For both MHCI and MHCII the T-cell peptide with the strongest affinity to the worldwide population was FSIPYTSPL.

Peptide vaccine against $\mathrm{AiV}$ is powerfully displace the normal produced vaccines based on the experimental biochemistry tools, as it designed to handle with a wide range of mutated strains, which will effectively minimize the frequent outbreaks and their massive economical wastage consequences.
\end{abstract}

Keywords: immunoinformatic, peptide vaccine, Epitope, Aichi virus, immune epitope database IEDB. 


\section{Introduction:}

Aichi virus 1 (AiV-1) is a small round virus its diameter is about $30 \mathrm{~nm}$, belongs to the Kobuvirus genus, Picornaviridae family, has been considered as the responsible agent for human gastroenteritis and children hospitalization with acute diarrhea probably passed by fecal-oral ways through polluted water or food(3-1).

In 1989, Aichi virus has been identified for the first time, as the likely cause of oysterrelated nonbacterial gastroenteritis in a stool specimen of a Japanese patient. AiV-1 was also identified in many Asian countries, for example, 5 (2.3\%) of 222 Pakistani children between 1990-1991, and 5 (0.7\%) of 722 Japanese travelers returned from tours to Southeast Asian countries between April 1990 and March 1992, the RNA was detected in $54(55 \%)$ of 99 fecal specimens from the patients in $12(32 \%)$ of 37 gastroenteritis epidemics in Japan.

In Finland, Of the 468 stool samples analyzed from the hospital-based epidemiological study, three samples were -positive for Aichi virus (0-6\% incidence), a 485 German serum samples panel was presented for Aichi virus antibody, identifying a seroprevalence of 76\%. Aichi virus was also found in 28 of 912 fecal samples which were negative for astrovirus, sapovirus, norovirus, adenovirus, and rotavirus and were assembled in Japan, Bangladesh, Thailand, and Vietnam during 2002 to 2005. A research carried out from January 2003 to June 2005 revealed, Aichi virus was the cause of $3.5 \%$ of 632 cases of Tunisian children presenting in hospitalization ( 252 children) or dispensaries (380children) for acute diarrhea. In Italy, the virus was found in 3/170 $(1.8 \%)$ of the analyzed specimens. The AiV-1 positive samples were of various geographic origin $(1,4-9)$.

The genome length of AiV-1 is about 8,400 nucleotides, $\mathrm{t}$ is positive sense, single stranded RNA, containing an open reading frame encoding a 2,433-residue long polyprotein. The polyprotein cleaves co-translationally and post-translationally to viral capsid proteins VP0, VP3, and VP1, leader protein (L-protein) and nonstructural proteins that control the $\mathrm{AiV}-1$ replication in the infected cell $(10,11)$.

On the outer surface, a polyproline helix structure, which was not identified formerly in picornaviruses, exists at the VP1 C terminus, a place where integin binding motifs are found in many other picornaviruses. A peptide linked to this polyproline motif attenuates virus infectivity to some extent, possibly blocking host-cell attachment. This may guide cellular receptor identification(12).

AiV can cause severe gastroenteritis and could be lethal for children below five years old, especially in developing countries. Moreover, there is no available vaccine or effective antiviral treatment has been introduced(12).

Our aim is to design a vaccine for Aichi virus using peptide of its vp1 as an immunogen to stimulate an immune response. 
Producing vaccine with the experimental biochemistry tools are high-cost, laborious and sometimes does not work effectively, moreover, the vaccine that formulated from attenuated or inactivated microorganism contains immunity induction proteins of that probably develops allergenic or reactogenic responses. For that reason, in silico proper protein residues epitopes prediction is considered to be helpful in peptide vaccine production with a great impact immunogenic and little amount of allergenic effect (13-16). Numerous researches demonstrated the immunological efficacy of peptide-based vaccines against infectious illnesses. The advancement of peptide-based immunizations has fundamentally progressed with the particular epitope's identification gotten from infectious pathogens. Comprehension of the antigen recognition molecular basis and HLA binding motifs has brought about the improvement of the designed vaccine depending on motifs prediction to bind to host class I or class II MHC(17). There are several types of research have been conducted considering immunoinformatic predication and in sillico modeling of epitope-based peptide vaccine against many viruses $(18-22)$.

\section{Materials \& Method:}

\subsection{Sequence of protein recovery:}

A total of 38 protein strains sequences of Aichi virus vp1 were retrieved from NCBI (https://www.ncbi.nlm.nih.gov/) in October 2018. Those 38 strains sequences were collected from different parts in the world (Japan, Germany and South Korea), The Achi virus VP1 strains, area of collection and their accession numbers are listed in the table (1).

\subsection{Phylogenetic and alignment:}

The retrieved sequences were submitted to Phylogenetic and alignment tools MEGA7.0 to determine the common ancestor of each strain and the conservancy (23) (https://www.megasoftware.net/). The alignment and phylogenetic tree were presented in Figure (2).

\subsection{Determination of conserved regions:}

The chosen sequences were aligned by using multiple sequence alignment (MSA) BioEdit software (version 7.2.5.0) (24) to obtain the sequences of the conserved regions, aligned with Clustal $\mathrm{W}$ were used to determine the conserved regions in all Aichi virus VP1, protein sequences shown in figure(3). Peptides chose as epitopes were analyzed by different prediction tools from Immune Epitope Database, IEDB analysis resource (https://www.iedb.org/ ) (25).

\subsection{Binding prediction of B cell epitope:}

The reference sequence of Aichi virus VP1 was subjected to many B cell tests in IEDB webpage ( http://tools.iedb.org/bcell/ ) (26).

\subsection{1 linear $B$ cell epitopes prediction:}

The linearity of the peptide was studied using Bepipered Linear Epitope Prediction in the immune epitope database ( http://toolsiedb.ofg/bcell/ ) (27), which had a threshold value of 0.35 .

\subsubsection{Surface accessibility prediction:}


Using Emini surface epitope prediction from IEDB (http://tools.immuneepitope.org/tools/bcell/iedb ) (28), Epitopes of the surface accessible were predicted from the region in which threshold holding value was 1.

\subsubsection{Epitope antigenicity prediction:}

kolaskar and tongaonker antigenicity in IEDB (http://tools. immuneepitope.org/bcell/) (29) was used to determine the antigenic sites with a default threshold value of 1.010.

\subsection{Binding prediction of $\mathrm{T}$ cell epitope:}

\subsubsection{Binding predictions of MHC class 1:}

The peptide binding analysis to major histocompatibility class I molecules was evaluated by IEDB MHC I estimated tool at ( http://tools.iedb.org/mhci/).

Prediction methods were achieved by Artificial Neural Network (ANN), The analysis was done for alleles with peptides length of 9-mers and which have scored equal or less than 500 Half Maximal Inhibitory Concentration (IC50) (30) which was chosen for further analysis.

\subsubsection{Binding Predictions of MHC class 2:}

Analysis of peptide binding to MHC2 molecules was assessed by the IEDB MHC II prediction tool at (http://tools.immuneepitope.org/mhcii/) (31) For MHCII binding Prediction human allele references set were used (32). We used Artificial Neural Networks (ANN) to identify both the binding affinity and MHCII binding core epitopes. All conserved epitopes that bind to many alleles with a score equal or less than 500 half maximal inhibitory concentration (IC50) were selected for further analysis.

\subsection{Population Coverage Calculation:}

All proposed MHC class I \& class II epitopes from Aichi virus vp1 protein were used for population coverage to whole world population with selected MHC I and MHC II binding alleles using IEDB population coverage calculation tool at (http://tools.iedb.org/tools/population/iedb_input) (33).

\subsection{Homology Modeling:}

The reference sequence of Aichi virus protein was sent to $\mathrm{CPH}$ server (http://www.cbs.dtu.dk/services/CPHmodels/index_prf2013.php) (34) to determine the 
3D structure. This 3D structure was visualized using chimera version (1.8) from chimera package that accessed from the chimera web site (https://www.cgl.ucsf.edu/chimera/docs/credits.html) (35).

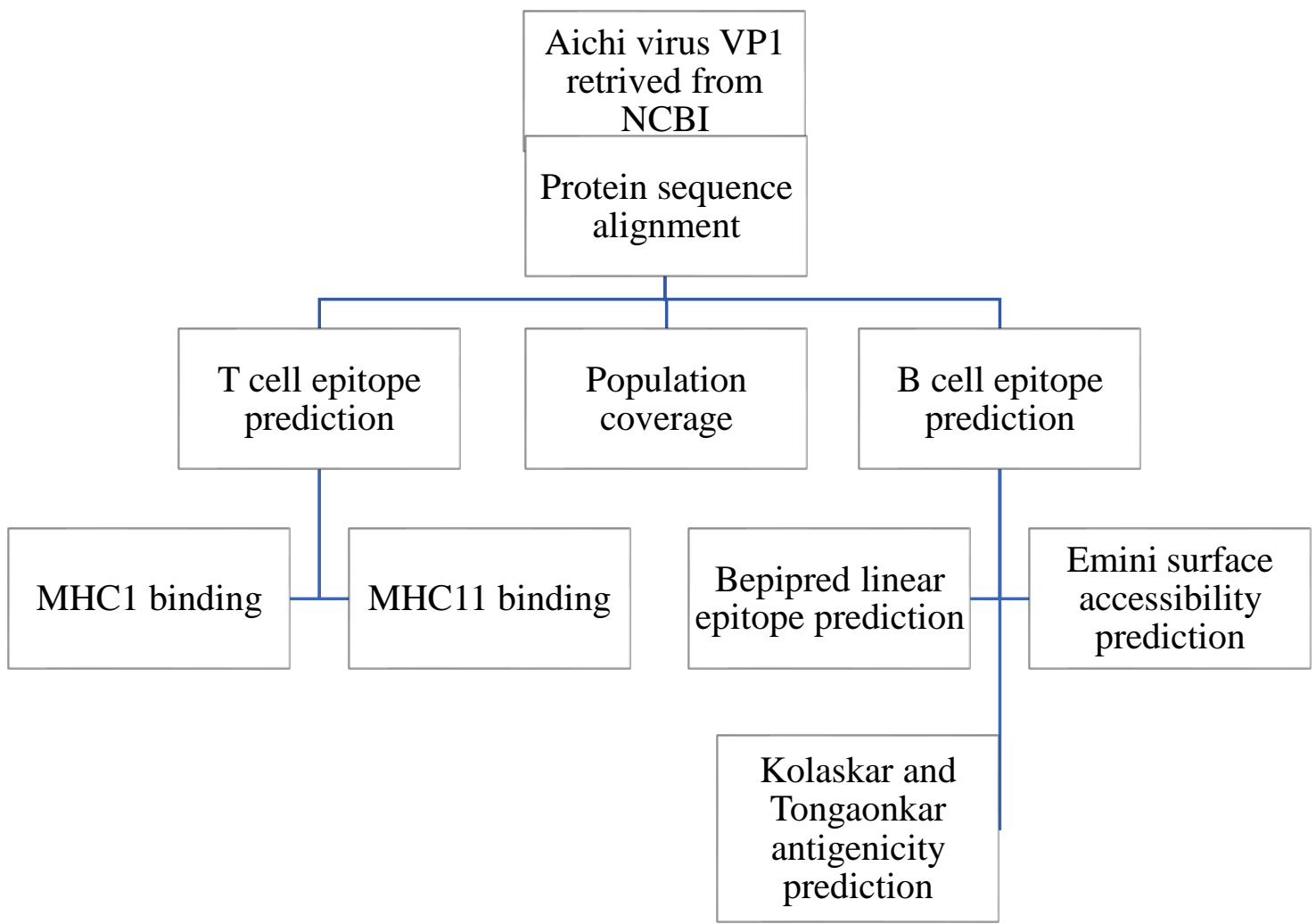

figure (1): Flowchart of the epitope prediction processes for B cell and T cell.

\section{Results:}

Table (1): virus strains, accession numbers, areas and years of collection:

\section{Accession number \\ Date of collection \\ Country}

$\begin{array}{llc}\text { NP_740437.1 } * & 1998 & \text { Japan } \\ \text { AGU13441.1 } & 2014 & \text { South Korea } \\ \text { AGU13442.1 } & 2014 & \text { South Korea } \\ \text { AGU13443.1 } & 2014 & \text { South Korea } \\ \text { AGU13444.1 } & 2014 & \text { South Korea } \\ \text { AGU13445.1 } & 2014 & \text { South Korea } \\ \text { AGU13446.1 } & 2014 & \text { South Korea }\end{array}$




\begin{tabular}{|c|c|c|}
\hline AGU13447.1 & 2014 & South Korea \\
\hline AGU13448.1 & 2014 & South Korea \\
\hline AGU13449.1 & 2014 & South Korea \\
\hline AGU13450.1 & 2014 & South Korea \\
\hline AGU13451.1 & 2014 & South Korea \\
\hline AGU13452.1 & 2014 & South Korea \\
\hline AGU13458.1 & 2014 & South Korea \\
\hline AGU13457.1 & 2014 & South Korea \\
\hline AGU13456.1 & 2014 & South Korea \\
\hline AGU13455.1 & 2014 & South Korea \\
\hline AGU13454.1 & 2014 & South Korea \\
\hline AGU13453.1 & 2014 & South Korea \\
\hline AGV23419.1 & 2011 & South Korea \\
\hline AGV23418.1 & 2011 & South Korea \\
\hline AGV23416.1 & 2010 & South Korea \\
\hline AGV23415.1 & 2010 & South Korea \\
\hline ADN52310.1 & 2012 & Germany \\
\hline AGV23417.1 & 2011 & South Korea \\
\hline ADN52309.1 & 2012 & Germany \\
\hline ADN52308.1 & 2012 & Germany \\
\hline ADN52307.1 & 2012 & Germany \\
\hline AGU13468.1 & 2014 & South Korea \\
\hline AGU13467.1 & 2014 & South Korea \\
\hline AGU13466.1 & 2014 & South Korea \\
\hline AGU13465.1 & 2014 & South Korea \\
\hline AGU13464.1 & 2014 & South Korea \\
\hline
\end{tabular}




\begin{tabular}{lll}
\hline AGU13463.1 & 2014 & South Korea \\
AGU13462.1 & 2014 & South Korea \\
AGU13461.1 & 2014 & South Korea \\
AGU13460.1 & 2014 & South Korea \\
AGU13459.1 & 2014 & South Korea \\
\hline
\end{tabular}

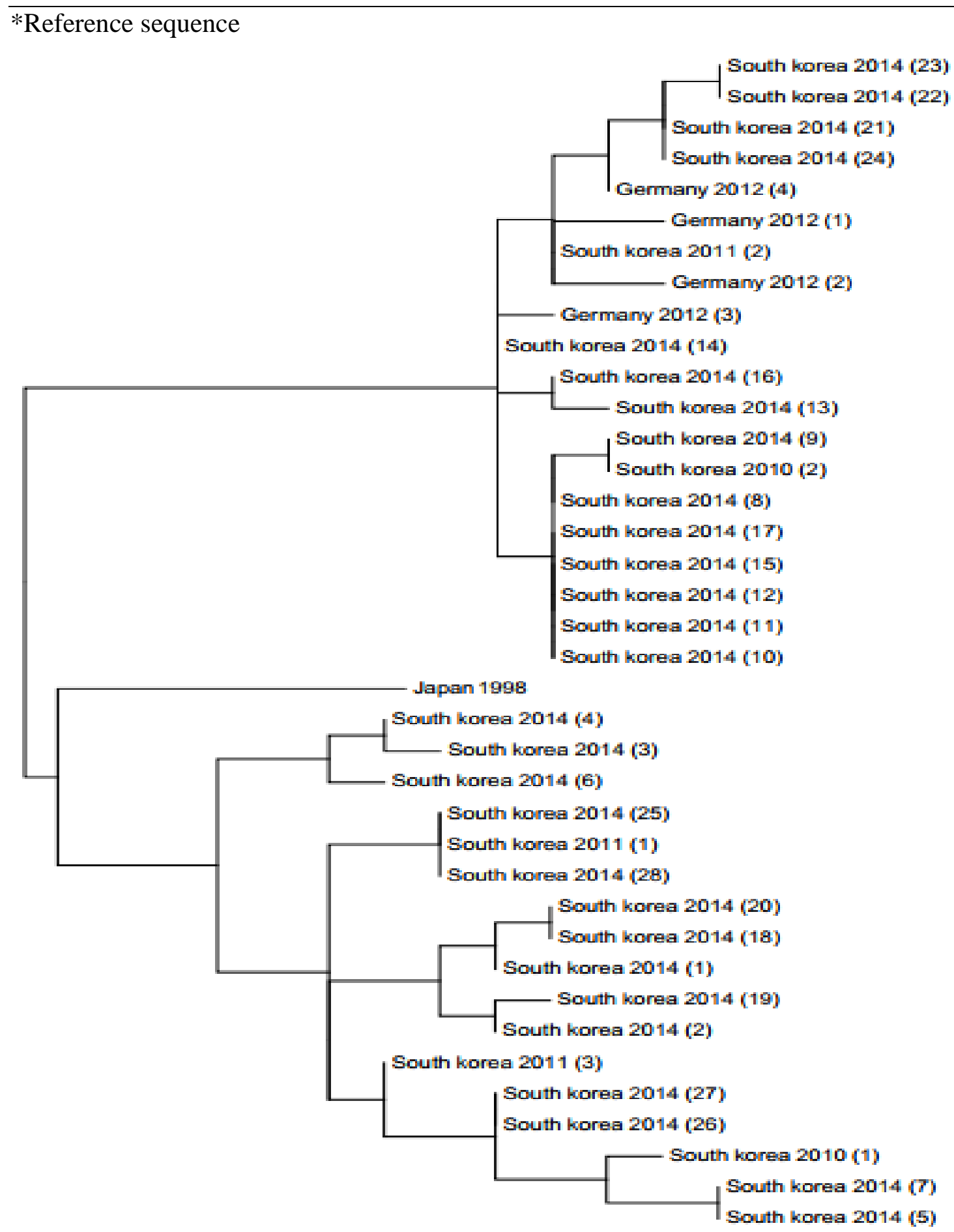

Figure (2): Cladogram shows the relationship between different strains of Aichi virus. 
bioRxiv preprint doi: https://doi.org/10.1101/795427; this version posted October 8,2019 . The copyright holder has placed this preprint

(which was not certified by peer review) in the Public Domain. It is no longer restricted by copyright. Anyone can legally share, reuse, remix, or adapt this material for any purpose without crediting the original authors.
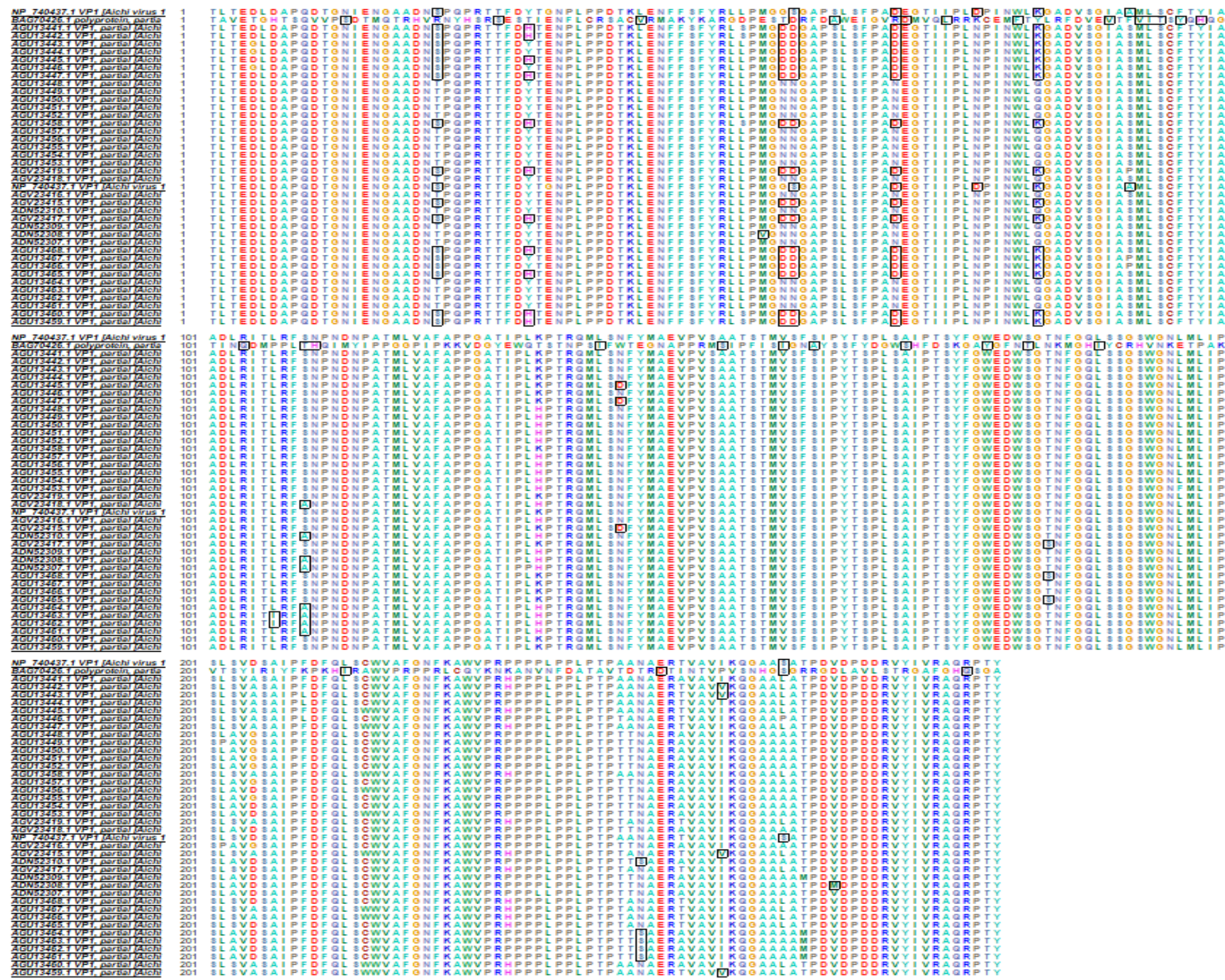

Figure (3): Protein sequence Alignment using Bioedit software for a showing of the conservancy.

\subsection{B-cell epitope prediction:}

The Bepipred linear epitope prediction, Kolaskar, and Tongaonkar results and Emini surface accessibility prediction results were recorded by subjected reference sequence of Aichi virus (vp1) in IEDB table 2, figures 4, 5 and 6.

Table (2): Results of B-cell epitopes prediction.

\begin{tabular}{cccccc}
\hline Epitope & Start & End & Length & Surface & Antigenicity \\
\hline LDAPQ & 6 & 10 & 5 & 1.158 & 1.052 \\
NPLP & 35 & 38 & 4 & 1.249 & 1.038
\end{tabular}




\begin{tabular}{|c|c|c|c|c|c|}
\hline PLPP & 36 & 39 & 4 & 1.201 & 1.111 \\
\hline LPPD & 37 & 40 & 4 & 1.297 & 1.061 \\
\hline NPLPP & 35 & 39 & 5 & 1.525 & 1.044 \\
\hline PLPPD & 36 & 40 & 5 & 1.583 & 1.062 \\
\hline LPPDT & 37 & 41 & 5 & 1.478 & 1.031 \\
\hline PLPPDT* $*$ & 36 & 41 & 6 & 1.831 & 1.036 \\
\hline TSPLS & 164 & 168 & 5 & 1.028 & 1.049 \\
\hline QLSS & 187 & 190 & 4 & 1.01 & 1.072 \\
\hline PPLP & 235 & 238 & 4 & 1.201 & 1.111 \\
\hline PLPT & 236 & 239 & 4 & 1.121 & 1.072 \\
\hline LPTP & 237 & 240 & 5 & 1.121 & 1.072 \\
\hline PPLPT & 235 & 239 & 5 & 1.368 & 1.07 \\
\hline PLPTP & 236 & 240 & 5 & 1.368 & 1.07 \\
\hline PPLPTP* & 235 & 240 & 6 & 1.695 & 1.069 \\
\hline LPPLPTP* & 234 & 240 & 7 & 1.103 & 1.095 \\
\hline
\end{tabular}

*Top epitopes in B-cell epitopes prediction

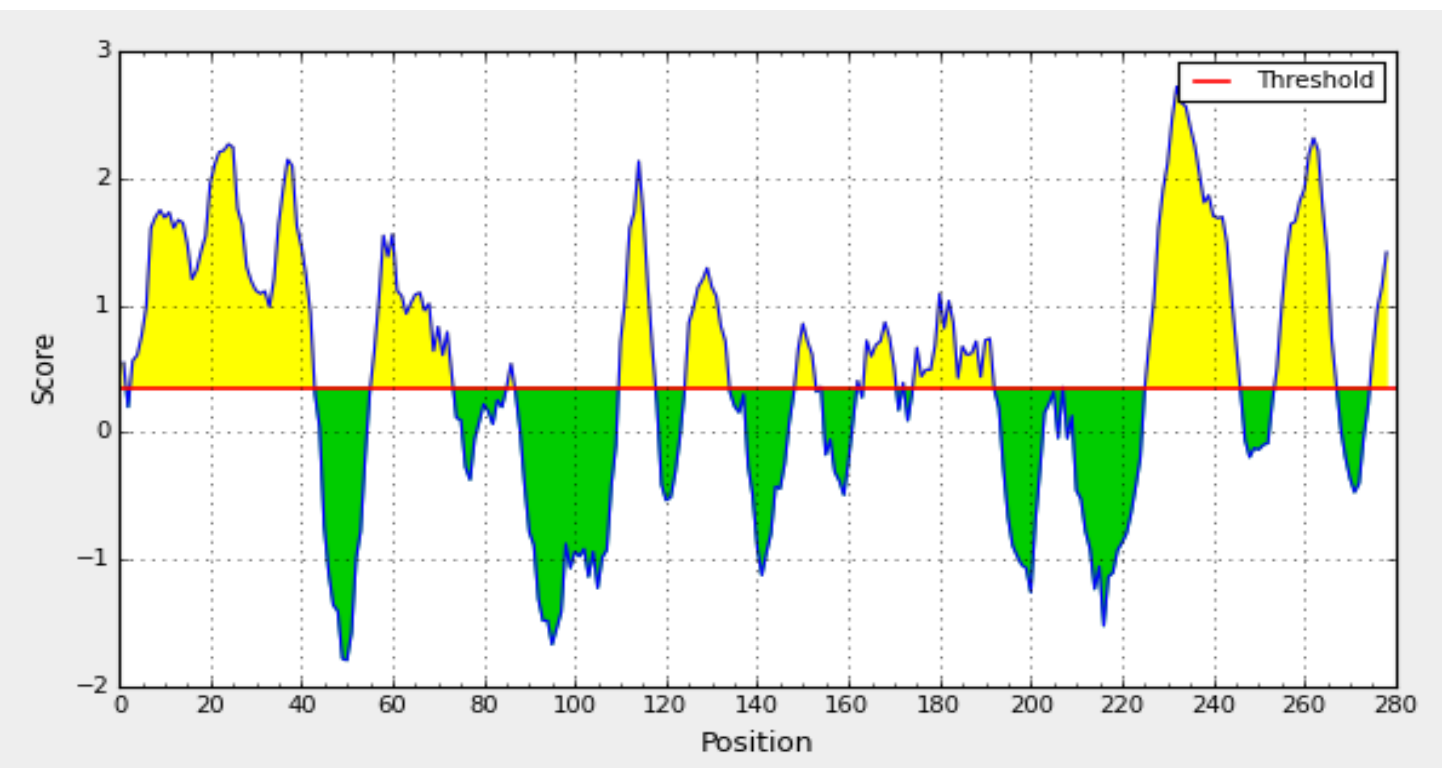

Figure (4): Bepipred linear epitope prediction. Yellow areas above threshold (red line) are proposed to be a part of B cell epitope. While green areas are not. 


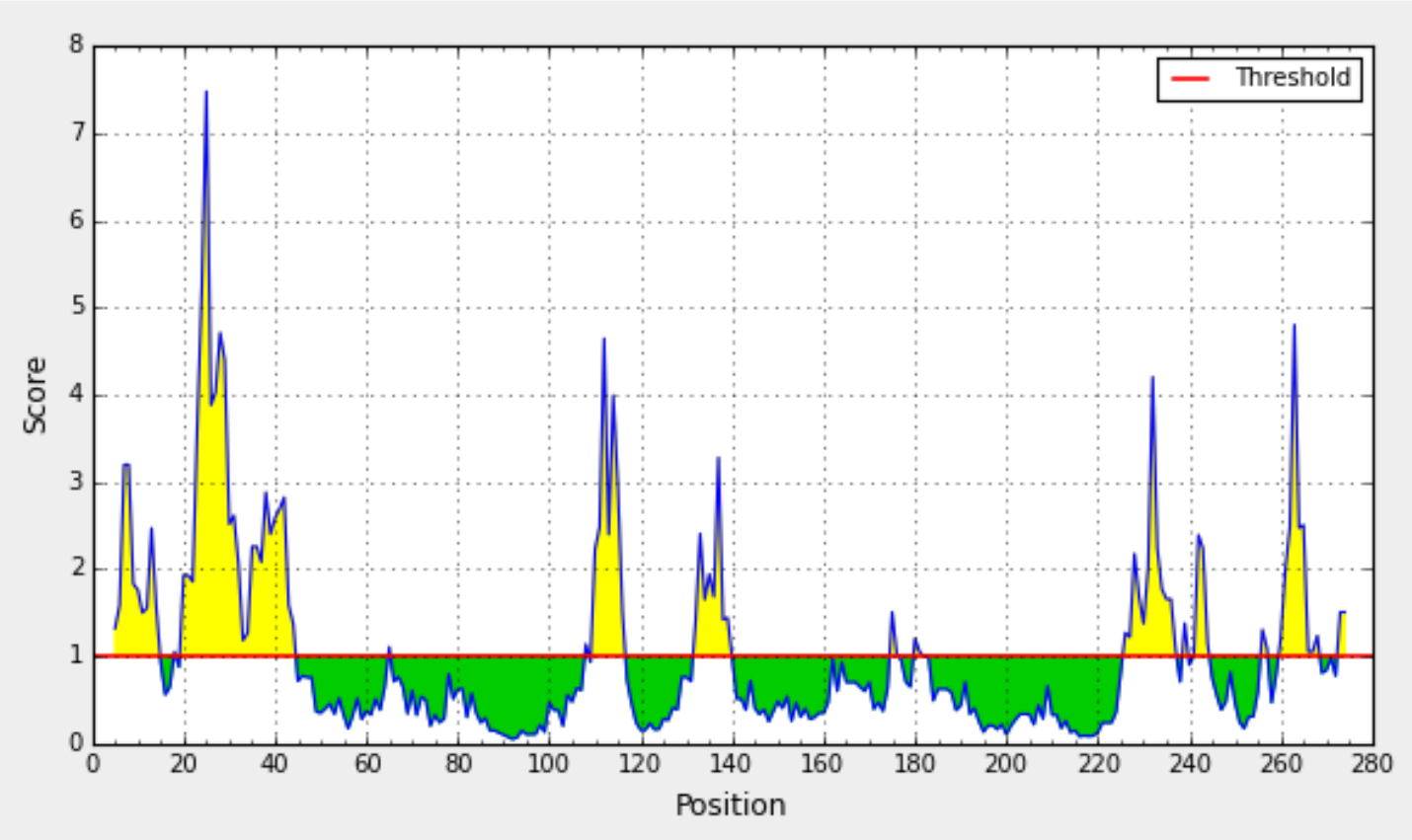

Figure (5): Emini surface accessibility. Yellow areas above threshold (red line) are proposed to be a part of B cell epitope. While green areas are not.

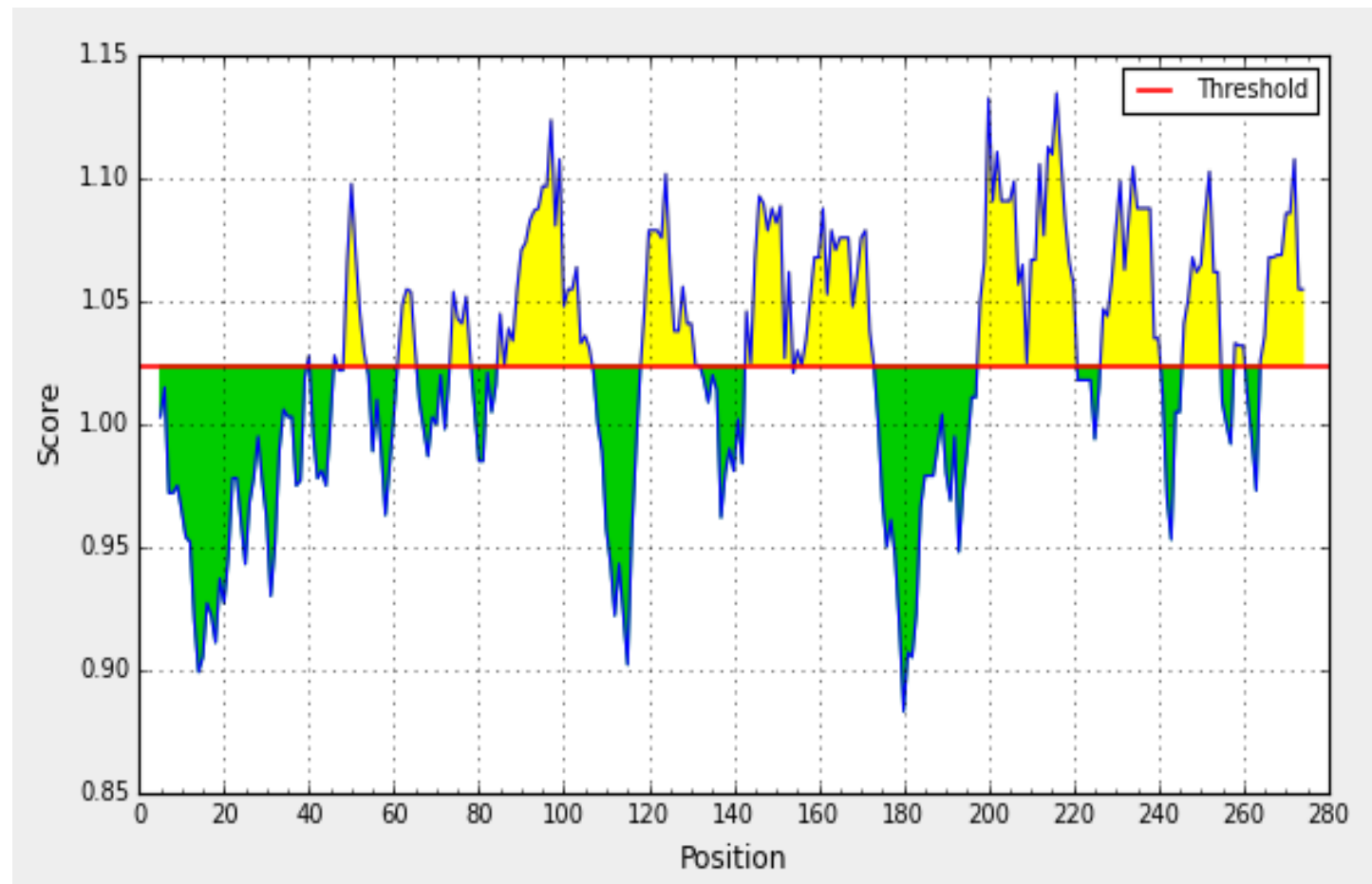

Figure (6): Kolaskar and togaonkar antigenicity. Yellow areas above threshold (red line) are proposed to be a part of B cell epitope. While green areas are not. 


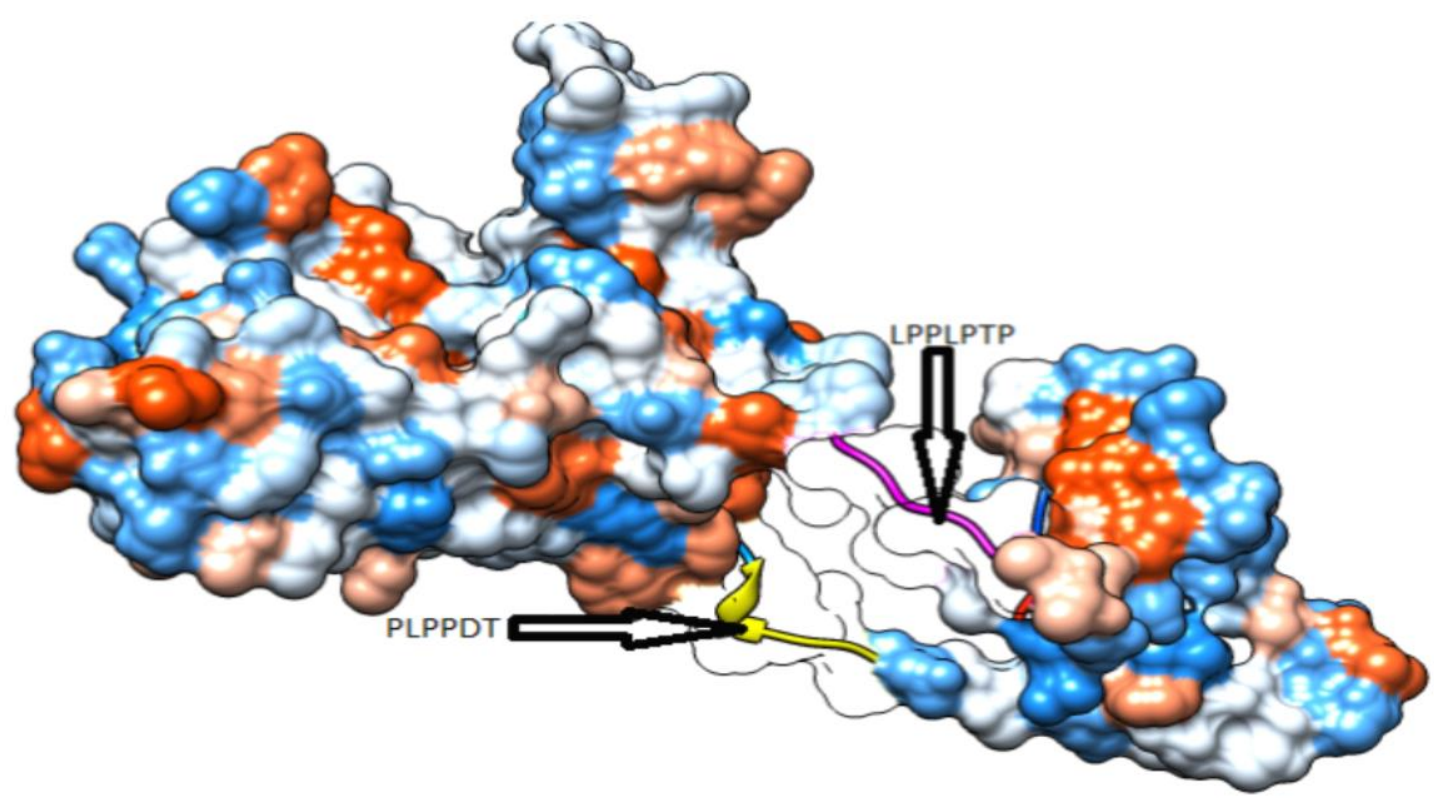

Figure (7): 3D structure of predicted B cell epitopes of vp1 Protein in Aichi virus

\subsection{Prediction of cytotoxic T-lymphocyte epitope and interaction with MHC 1}

The (vp1) reference sequence protein of Aichi virus was submitted in the IEDB MHC1 binding prediction tool to predict epitopes interact with MHC-1 alleles.

Table (3): Result of predicted peptides that interact with MHC1:

\begin{tabular}{cccccc}
\hline Peptide & Start & End & Allele & ic50 & $\begin{array}{c}\text { Percentile } \\
\text { Rank }\end{array}$ \\
\hline AADLRITLR & 100 & 108 & HLA-A*31:01 & 353.19 & 2.5 \\
AAMLSCFTY & 90 & 98 & HLA-A*11:01 & 110.04 & 0.74 \\
& & & HLA-A*29:02 & 288.43 & 0.99 \\
& & & HLA-A*30:02 & 117.21 & 0.42 \\
& & & HLA-B*15:01 & 232.88 & 0.95 \\
& & & HLA-B*35:01 & 19.01 & 0.09 \\
AATSTMVSF & \multirow{2}{*}{151} & \multirow{2}{*}{159} & HLA-B*58:01 & 343.48 & 0.81 \\
& & & HLA-B*15:01 & 168.54 & 0.78 \\
ALVPVSAAT & \multirow{2}{*}{145} & \multirow{2}{*}{153} & HLA-B*35:01 & 198.8 & 0.47 \\
& & & HLA-C*03:03 & 86.19 & 0.3 \\
AFAPPGATI & \multirow{2}{*}{122} & 130 & HLA-B*44:02 & 445.71 & 0.5 \\
AMLSCFTYI & 91 & 99 & HLA-C*03:03 & 26.95 & 0.14 \\
& & & HLA-A*02:01 & 5.2 & 0.04 \\
& & & HLA-A*02:06 & 4.05 & 0.02 \\
\hline
\end{tabular}




\begin{tabular}{|c|c|c|c|c|c|}
\hline & & & HLA-A*23:01 & 472.48 & 0.92 \\
\hline & & & HLA-A*31:01 & 403.15 & 2.7 \\
\hline ANAERTVAV & 242 & 250 & HLA-B*14:02 & 495.45 & 0.03 \\
\hline \multirow[t]{4}{*}{ APPGATIPL } & 124 & 132 & HLA-B*07:02 & 17.21 & 0.06 \\
\hline & & & HLA-B*35:01 & 332.09 & 0.64 \\
\hline & & & HLA-B*39:01 & 236.98 & 0.19 \\
\hline & & & HLA-C*14:02 & 149.82 & 0.24 \\
\hline \multirow[t]{3}{*}{ ATIPLKPTR } & 128 & 136 & HLA-A*11:01 & 113.96 & 0.76 \\
\hline & & & HLA-A*31:01 & 28.09 & 0.37 \\
\hline & & & HLA-A*68:01 & 54.58 & 0.49 \\
\hline DTGNIENGA & 11 & 19 & HLA-A*68:02 & 395.59 & 1.6 \\
\hline \multirow[t]{2}{*}{ DVSGIAAML } & 85 & 93 & HLA-A $* 26: 01$ & 494.86 & 0.23 \\
\hline & & 93 & HLA-A*68:02 & 13.02 & 0.13 \\
\hline ENFFSFYRL & 44 & 52 & HLA-A*68:02 & 28.77 & 0.26 \\
\hline \multirow[t]{2}{*}{ FAPPGATIP } & 123 & 131 & HLA-C*03:03 & 292.01 & 0.57 \\
\hline & & & HLA-C*12:03 & 113.51 & 0.2 \\
\hline \multirow[t]{3}{*}{ FDFQLSCWV } & 210 & 218 & HLA-A*02:06 & 258.78 & 1.8 \\
\hline & & & HLA-B $* 40: 02$ & 403.14 & 0.8 \\
\hline & & & HLA-C*12:03 & 181.25 & 0.27 \\
\hline FFSFYRLLP & 46 & 54 & HLA-A*29:02 & 458.65 & 1.4 \\
\hline \multirow[t]{8}{*}{ FPADEGTII } & 65 & 73 & HLA-B*07:02 & 257.69 & 0.79 \\
\hline & & & HLA-B*35:01 & 64.83 & 0.23 \\
\hline & & & HLA-B $* 35: 03$ & 510.8 & 0.02 \\
\hline & & & HLA-B*39:01 & 210.19 & 0.18 \\
\hline & & & HLA-B*51:01 & 53.16 & 0.02 \\
\hline & & & HLA-B $* 53: 01$ & 23.49 & 0.04 \\
\hline & & & HLA-C*03:03 & 491.63 & 0.72 \\
\hline & & & HLA-C*12:03 & 309.92 & 0.39 \\
\hline \multirow[t]{11}{*}{ FQLSCWVAF } & 212 & 220 & HLA-A*02:06 & 4.51 & 0.03 \\
\hline & & & HLA-A $* 23: 01$ & 126.08 & 0.39 \\
\hline & & & HLA-A*32:01 & 56.3 & 0.09 \\
\hline & & & HLA-B*15:01 & 27.21 & 0.16 \\
\hline & & & HLA-B*15:02 & 57 & 0.03 \\
\hline & & & HLA-B $* 27: 05$ & 218.13 & 0.8 \\
\hline & & & HLA-B*35:01 & 52.93 & 0.2 \\
\hline & & & HLA-B*39:01 & 70.72 & 0.1 \\
\hline & & & HLA-B $* 48: 01$ & 346.81 & 0.03 \\
\hline & & & HLA-C*07:02 & 342.25 & 0.08 \\
\hline & & & HLA-C*12:03 & 360.79 & 0.43 \\
\hline \multirow[t]{3}{*}{ FSFYRLLPM } & 47 & 55 & HLA-A*02:01 & 446.07 & 2.8 \\
\hline & & & HLA-A $* 02: 06$ & 70.28 & 0.71 \\
\hline & & & HLA-A*29:02 & 175.92 & 0.75 \\
\hline
\end{tabular}




\begin{tabular}{|c|c|c|c|c|c|}
\hline & & & HLA-A*68:02 & 174.16 & 0.87 \\
\hline & & & HLA-B*08:01 & 36.41 & 0.1 \\
\hline & & & HLA-B*14:02 & 210.88 & 0.02 \\
\hline & & & HLA-B*15:01 & 65.94 & 0.36 \\
\hline & & & HLA-B*35:01 & 65.86 & 0.23 \\
\hline & & & HLA-B $* 46: 01$ & 25.06 & 0.02 \\
\hline & & & HLA-C*03:03 & 13.07 & 0.08 \\
\hline & & & HLA-C*06:02 & 309.01 & 0.11 \\
\hline & & & HLA-C*12:03 & 13.46 & 0.03 \\
\hline & & & HLA-C*14:02 & 102.48 & 0.18 \\
\hline & & & HLA-C*15:02 & 25.32 & 0.02 \\
\hline \multirow[t]{14}{*}{ FSIPYTSPL* } & 159 & 167 & HLA-A*02:01 & 56.39 & 0.6 \\
\hline & & & HLA-A*02:06 & 8.32 & 0.1 \\
\hline & & & HLA-A*68:02 & 8.29 & 0.08 \\
\hline & & & HLA-B*15:01 & 72.5 & 0.41 \\
\hline & & & HLA-B*35:01 & 60.58 & 0.22 \\
\hline & & & HLA-B*39:01 & 23 & 0.04 \\
\hline & & & HLA-B*46:01 & 107.8 & 0.02 \\
\hline & & & HLA-B*58:01 & 216.88 & 0.63 \\
\hline & & & HLA-C*03:03 & 2.54 & 0.02 \\
\hline & & & HLA-C*07:02 & 233.62 & 0.06 \\
\hline & & & HLA-C*08:02 & 516.41 & 0.04 \\
\hline & & & HLA-C*12:03 & 8.47 & 0.02 \\
\hline & & & HLA-C $* 14: 02$ & 12.17 & 0.03 \\
\hline & & & HLA-C* $15: 02$ & 25.16 & 0.02 \\
\hline \multirow[t]{4}{*}{ FSNPNDNPA } & 109 & 117 & HLA-A*68:02 & 92.14 & 0.6 \\
\hline & & & HLA-B*35:01 & 330.43 & 0.63 \\
\hline & & & HLA-C*03:03 & 103.18 & 0.32 \\
\hline & & & HLA-C*12:03 & 378.95 & 0.45 \\
\hline \multirow[t]{3}{*}{ FTYIAADLR } & 96 & 104 & HLA-A $* 11: 01$ & 387.17 & 2 \\
\hline & & & HLA-A*31:01 & 471.8 & 3 \\
\hline & & & HLA-A*68:01 & 5.05 & 0.02 \\
\hline FYMAEVPVS & 142 & 150 & HLA-C*14:02 & 64.17 & 0.12 \\
\hline GAPSLSFPA & 59 & 67 & HLA-A*02:06 & 187.62 & 1.5 \\
\hline GIAAMLSCF & 88 & 96 & HLA-B*15:01 & 40.27 & 0.23 \\
\hline \multirow[t]{2}{*}{ GNFKAWVPR } & 221 & 229 & HLA-A*31:01 & 35.14 & 0.45 \\
\hline & & & HLA-A*68:01 & 472.71 & 2.2 \\
\hline GSGAPSLSF & 57 & 65 & HLA-B $* 15: 01$ & 44.83 & 0.25 \\
\hline GSWGNLMLI & 191 & 199 & HLA-A*02:06 & 221.83 & 1.6 \\
\hline \multirow[t]{2}{*}{ GTIIPLDPI } & 70 & 78 & HLA-A*02:06 & 122.92 & 1.2 \\
\hline & & & HLA-A*68:02 & 148.68 & 0.78 \\
\hline IAADLRITL & 99 & 107 & HLA-A*02:06 & 317.92 & 2 \\
\hline
\end{tabular}




\begin{tabular}{|c|c|c|c|c|c|}
\hline & & & HLA-A*68:02 & 430.82 & 1.6 \\
\hline & & & HLA-B $* 35: 01$ & 194.83 & 0.46 \\
\hline & & & HLA-C*03:03 & 22.75 & 0.13 \\
\hline & & & HLA-C*12:03 & 39.88 & 0.1 \\
\hline \multirow[t]{2}{*}{ IPFDFQLSC } & 208 & 216 & HLA-B*35:01 & 425.9 & 0.75 \\
\hline & & & HLA-B $* 53: 01$ & 305.99 & 0.26 \\
\hline IPLDPINWL & 73 & 81 & HLA-B*07:02 & 446.47 & 1.3 \\
\hline \multirow[t]{2}{*}{ IPLKPTRQM } & 130 & 138 & HLA-B*07:02 & 9.34 & 0.03 \\
\hline & & & HLA-B*35:01 & 212.74 & 0.48 \\
\hline \multirow[t]{2}{*}{ IPYTSPLSA } & 161 & 169 & HLA-B*07:02 & 285.48 & 0.83 \\
\hline & & & HLA-B*35:01 & 439.16 & 0.76 \\
\hline \multirow[t]{5}{*}{ IVRAQRPTY } & 270 & 278 & HLA-A*29:02 & 284 & 0.98 \\
\hline & & & HLA-A $* 30: 01$ & 18.63 & 0.09 \\
\hline & & & HLA-A*30:02 & 279.86 & 1 \\
\hline & & & HLA-B*15:01 & 166.02 & 0.78 \\
\hline & & & HLA-B*35:01 & 257.8 & 0.54 \\
\hline KAWVPRPPP & 224 & 232 & HLA-A*30:01 & 187.1 & 0.5 \\
\hline \multirow[t]{5}{*}{ KLENFFSFY } & 42 & 50 & HLA-A*01:01 & 413.8 & 0.57 \\
\hline & & & HLA-A*03:01 & 120.86 & 0.51 \\
\hline & & & HLA-A*11:01 & 378.02 & 2 \\
\hline & & & HLA-A*29:02 & 205.44 & 0.82 \\
\hline & & & HLA-A $* 30: 02$ & 38.62 & 0.09 \\
\hline \multirow[t]{2}{*}{ LENFFSFYR } & 43 & 51 & HLA-A*31:01 & 15.08 & 0.18 \\
\hline & & & HLA-A*68:01 & 18.64 & 0.14 \\
\hline \multirow[t]{2}{*}{ LMLIPSLSV } & 196 & 204 & HLA-A*02:01 & 28.3 & 0.32 \\
\hline & & & HLA-A*02:06 & 56.59 & 0.6 \\
\hline \multirow[t]{2}{*}{ LPMGGSGAP } & 53 & 61 & HLA-B $* 07: 02$ & 123.88 & 0.45 \\
\hline & & & HLA-B*35:01 & 61.41 & 0.22 \\
\hline \multirow[t]{2}{*}{ LPPLPTPAA } & 234 & 242 & HLA-B*07:02 & 341.25 & 0.96 \\
\hline & & & HLA-B*35:01 & 434.78 & 0.76 \\
\hline LPTPAANAE & 237 & 245 & HLA-B*35:01 & 61.67 & 0.22 \\
\hline LRITLRFSN & 103 & 111 & HLA-B*27:05 & 479.83 & 1.7 \\
\hline \multirow[t]{5}{*}{ LSAIPTSYF } & 167 & 175 & HLA-B*15:01 & 60.29 & 0.34 \\
\hline & & & HLA-B $* 57: 01$ & 433.4 & 1 \\
\hline & & & HLA-B*58:01 & 52.02 & 0.24 \\
\hline & & & HLA-B*58:02 & 12684.19 & 0.84 \\
\hline & & & HLA-C*05:01 & 69.32 & 0.08 \\
\hline \multirow[t]{3}{*}{ LSNFYMAEV } & 139 & 147 & HLA-A $* 02: 06$ & 352.33 & 2.1 \\
\hline & & & HLA-A*68:02 & 44.16 & 0.36 \\
\hline & & & HLA-C*15:02 & 79.21 & 0.05 \\
\hline \multirow[t]{2}{*}{ LSVDSAIPF } & 202 & 210 & HLA-A $* 02: 06$ & 203.16 & 1.6 \\
\hline & & & HLA-B*15:01 & 16.26 & 0.08 \\
\hline
\end{tabular}




\begin{tabular}{|c|c|c|c|c|c|}
\hline & & & HLA-B*35:01 & 16.99 & 0.08 \\
\hline & & & HLA-B*58:01 & 108.71 & 0.42 \\
\hline & & & HLA-C $* 03: 03$ & 54.63 & 0.21 \\
\hline & & & HLA-C*12:03 & 493.41 & 0.54 \\
\hline LVAFAPPGA & 120 & 128 & HLA-A*68:02 & 321.38 & 1.4 \\
\hline \multirow[t]{3}{*}{ MLSCFTYIA } & 92 & 100 & HLA-A*02:01 & 12.17 & 0.12 \\
\hline & & & HLA-A*02:06 & 103.12 & 0.96 \\
\hline & & & HLA-A*68:02 & 35.63 & 0.32 \\
\hline \multirow[t]{2}{*}{ MLVAFAPPG } & 119 & 127 & HLA-A $* 02: 01$ & 425.21 & 2.7 \\
\hline & & & HLA-A*02:06 & 376.36 & 2.2 \\
\hline \multirow[t]{2}{*}{ MVSFSIPYT } & 156 & 164 & HLA-A*02:01 & 351.5 & 2.4 \\
\hline & & & HLA-A*02:06 & 145.23 & 1.3 \\
\hline MVSFSIPYT & & & HLA-A*68:02 & 75.66 & 0.52 \\
\hline NAERTVAVI & 243 & 251 & HLA-C*12:03 & 247.09 & 0.33 \\
\hline NDNPATMLV & 113 & 121 & HLA-A*68:02 & 456.33 & 1.7 \\
\hline \multirow[t]{2}{*}{ NFFSFYRLL } & 45 & 53 & HLA-A*23:01 & 332.41 & 0.74 \\
\hline & & & HLA-C*07:01 & 429.43 & 0.12 \\
\hline \multirow[t]{2}{*}{ NFYMAEVPV } & 141 & 149 & HLA-A*68:02 & 397.17 & 1.6 \\
\hline & & & HLA-C*14:02 & 184.56 & 0.28 \\
\hline \multirow[t]{4}{*}{ NPATMLVAF } & 115 & 123 & HLA-B*07:02 & 70.83 & 0.27 \\
\hline & & & HLA-B*18:01 & 108.27 & 0.27 \\
\hline & & & HLA-B*35:01 & 4.96 & 0.02 \\
\hline & & & HLA-B*53:01 & 31.27 & 0.05 \\
\hline NPLPPDTKL & 35 & 43 & HLA-B*07:02 & 376.49 & 1.2 \\
\hline \multirow[t]{5}{*}{ NPNDNPATM } & 111 & 119 & HLA-B*07:02 & 371.9 & 1.2 \\
\hline & & & HLA-B*35:01 & 10.7 & 0.05 \\
\hline & & & HLA-B*39:01 & 233.01 & 0.19 \\
\hline & & & HLA-B*53:01 & 85.53 & 0.11 \\
\hline & & & HLA-C*03:03 & 480.46 & 0.71 \\
\hline PLSAIPTSY & 166 & 174 & HLA-A*29:02 & 147.15 & 0.68 \\
\hline PNDNPATML & 112 & 120 & HLA-C*05:01 & 391.31 & 0.19 \\
\hline PTPAANAER & 238 & 246 & HLA-A*68:01 & 480.4 & 2.2 \\
\hline PTRQMLSNF & 134 & 142 & HLA-A $* 25: 01$ & 511.55 & 0.05 \\
\hline PYTSPLSAI & 162 & 170 & HLA-C*14:02 & 311.97 & 0.41 \\
\hline \multirow[t]{2}{*}{ QMLSNFYMA } & 137 & 145 & HLA-A*02:01 & 36.86 & 0.4 \\
\hline & & & HLA-A*02:06 & 13.91 & 0.18 \\
\hline \multirow[t]{3}{*}{ RPPPPLPPL } & 229 & 237 & HLA-B*07:02 & 19.08 & 0.07 \\
\hline & & & HLA-C*14:02 & 161.29 & 0.25 \\
\hline & & & HLA-E*01:01 & 3245.96 & 0.06 \\
\hline \multirow[t]{3}{*}{ RQMLSNFYM } & 136 & 144 & HLA-A*02:01 & 59.7 & 0.63 \\
\hline & & & HLA-A*02:06 & 16.43 & 0.21 \\
\hline & & & HLA-A*30:01 & 430.44 & 0.82 \\
\hline
\end{tabular}




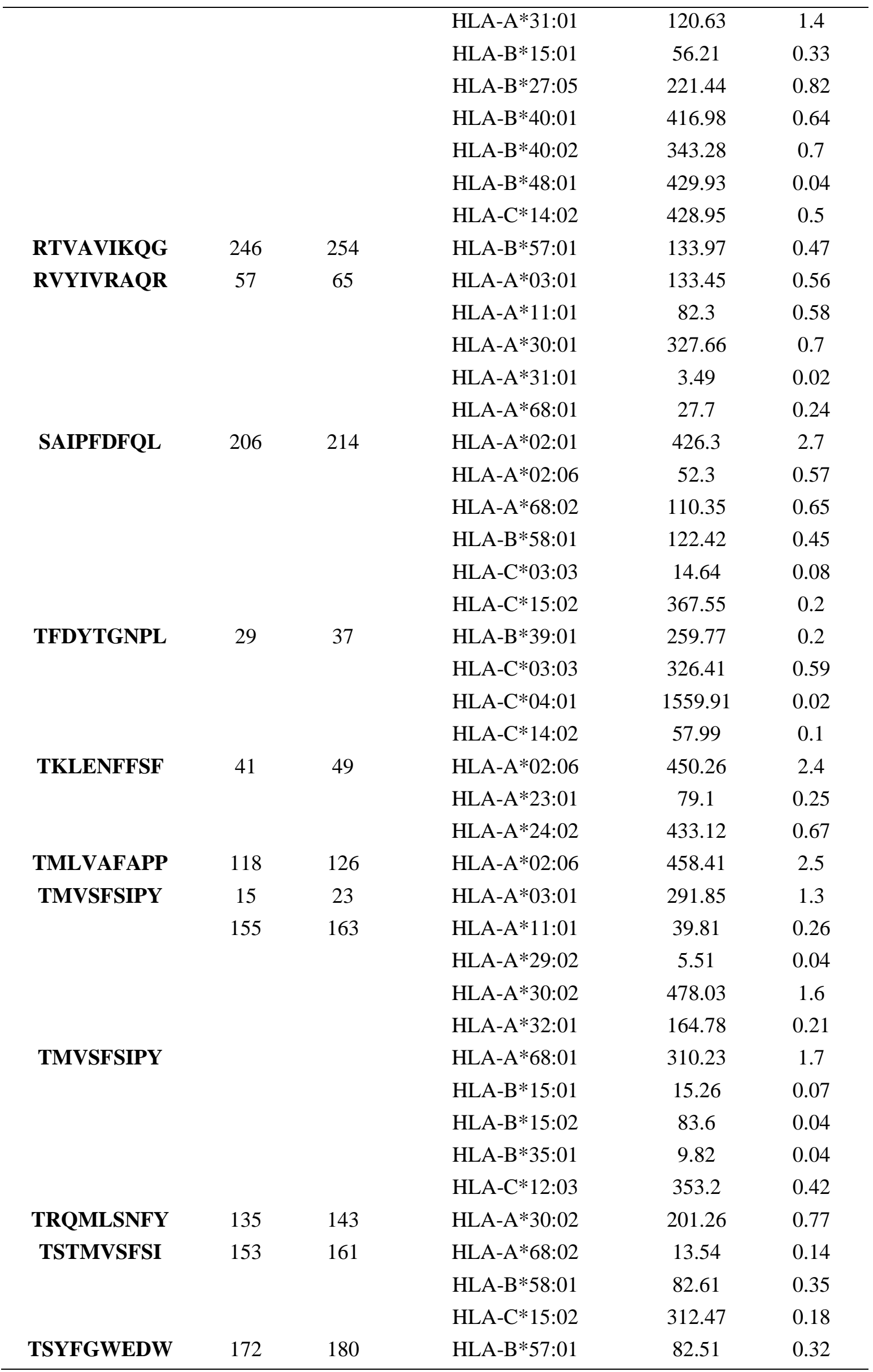




\begin{tabular}{|c|c|c|c|c|c|}
\hline & & & HLA-B*58:01 & 94.96 & 0.38 \\
\hline TVAVIKQGA & 247 & 255 & HLA-A $* 68: 02$ & 26.29 & 0.24 \\
\hline \multirow[t]{3}{*}{ TYIAADLRI } & 97 & 105 & HLA-A $* 23: 01$ & 25.88 & 0.1 \\
\hline & & & HLA-A $* 24: 02$ & 61.85 & 0.09 \\
\hline & & & HLA-C*14:02 & 349.06 & 0.44 \\
\hline \multirow[t]{2}{*}{ VAFAPPGAT } & 121 & 129 & HLA-C*03:03 & 60.11 & 0.23 \\
\hline & & & HLA-C*12:03 & 104.93 & 0.19 \\
\hline \multirow[t]{5}{*}{ VAFGNFKAW } & 218 & 226 & HLA-B*53:01 & 325.42 & 0.28 \\
\hline & & & HLA-B*57:01 & 33.47 & 0.13 \\
\hline & & & HLA-B*58:01 & 86.23 & 0.35 \\
\hline & & & HLA-C ${ }^{*} 03: 03$ & 22.1 & 0.13 \\
\hline & & & HLA-C*12:03 & 18.77 & 0.04 \\
\hline VPVSAATST & 147 & 155 & HLA-B*07:02 & 368.4 & 1.1 \\
\hline \multirow[t]{2}{*}{ VSAATSTMV } & 149 & 157 & HLA-A $* 88: 02$ & 117.3 & 0.67 \\
\hline & & & HLA-C*15:02 & 63.85 & 0.05 \\
\hline \multirow[t]{5}{*}{ WEDWSGTNF } & 177 & 185 & HLA-B*18:01 & 124 & 0.29 \\
\hline & & & HLA-B*38:01 & 2082.01 & 1.3 \\
\hline & & & HLA-B*40:01 & 13.69 & 0.04 \\
\hline & & & HLA-B $* 44: 03$ & 464.64 & 0.76 \\
\hline & & & HLA-C*05:01 & 239.09 & 0.15 \\
\hline \multirow[t]{2}{*}{ WVAFGNFKA } & 217 & 225 & HLA-A $* 02: 06$ & 226.99 & 1.7 \\
\hline & & & HLA-A*68:02 & 40.41 & 0.34 \\
\hline \multirow[t]{2}{*}{ WVPRPPPPL } & 226 & 234 & HLA-C*03:03 & 40.11 & 0.17 \\
\hline & & & HLA-C*14:02 & 93.35 & 0.17 \\
\hline \multirow[t]{5}{*}{ YMAEVPVSA* } & 143 & 151 & HLA-A $* 02: 01$ & 4.9 & 0.03 \\
\hline & & & HLA-A $* 02: 06$ & 21.81 & 0.26 \\
\hline & & & HLA-A*68:02 & 159.05 & 0.8 \\
\hline & & & HLA-B*15:01 & 455.7 & 1.7 \\
\hline & & & HLA-C $* 12: 03$ & 36.73 & 0.09 \\
\hline
\end{tabular}

*Top epitopes in MHC1 epitopes prediction 


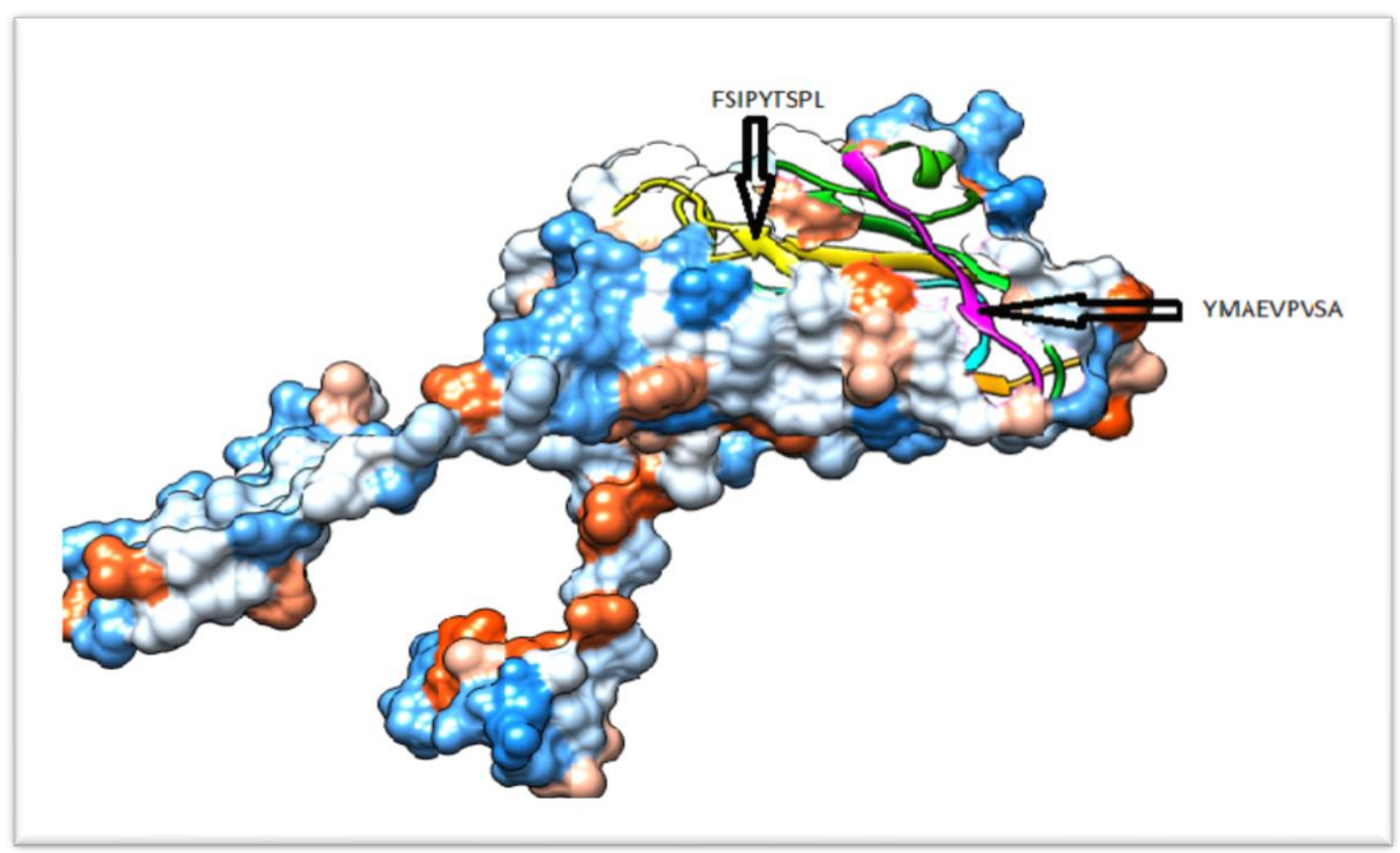

Figure (8): 3D structure of cytotoxic T cell epitopes interacts with MCH1

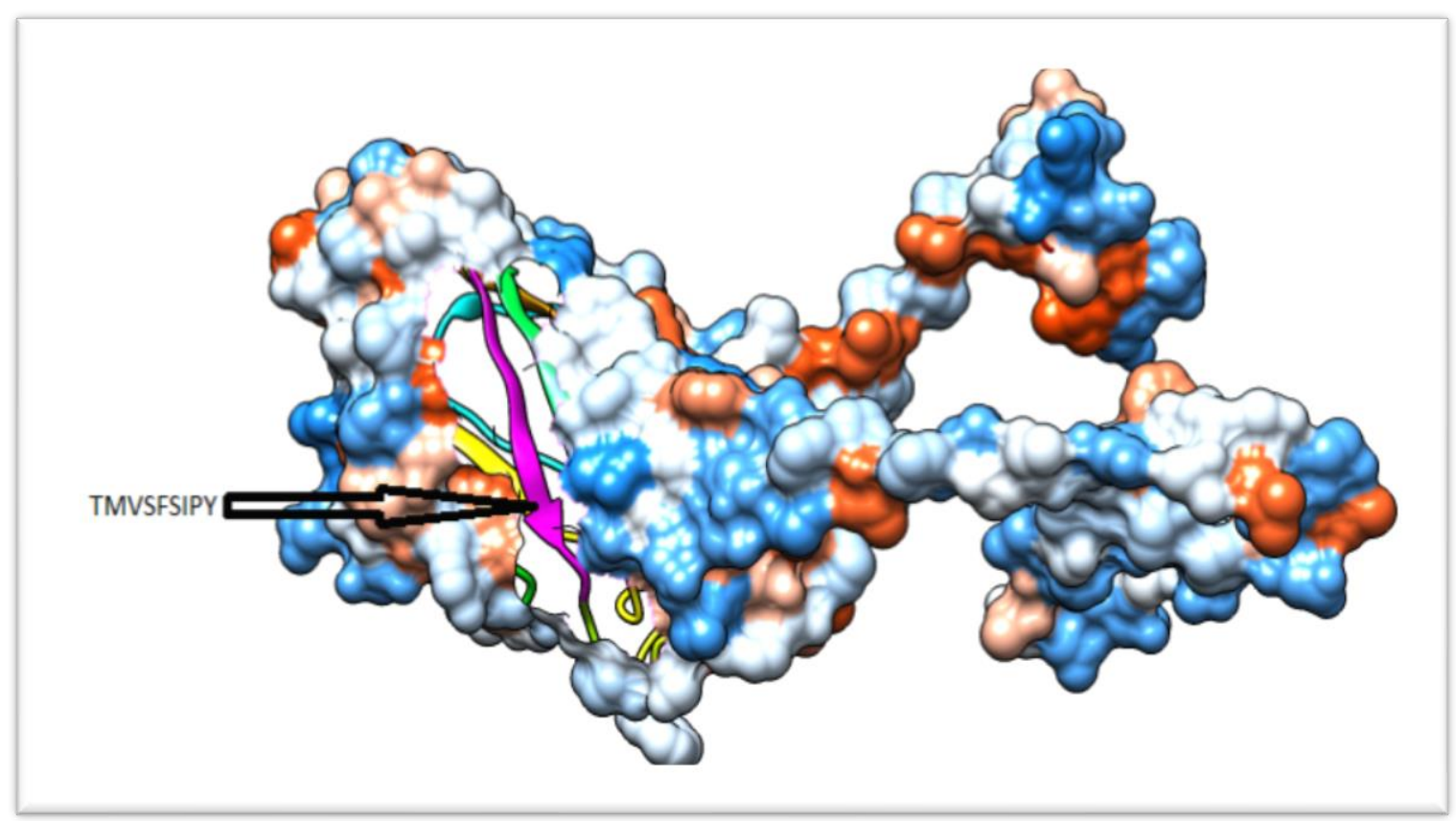

Figure (9): 3D structure of cytotoxic T cell epitopes interacts with MCH1

\subsection{Prediction of T-cell epitopes and interaction with MHC 11:}

The (vp1) reference sequence protein of Aichi virus was submitted in the IEDB MHC11 binding prediction tool to predict epitopes interact with MHC-11 alleles. 
Table (4): Some of the results of predicted peptides that interact with MHC 11; remaining data as an extra file.

\begin{tabular}{|c|c|c|c|c|c|c|}
\hline Core sequence & Start & End & Peptide sequence & Allele & IC50 & Rank \\
\hline AADLRITLR & 99 & 113 & IAADLRITLRFSNPN & HLA-DRB1*01:01 & 390.2 & 52.67 \\
\hline \multirow[t]{8}{*}{ AFGNFKAWV } & 214 & 228 & LSCWVAFGNFKAWVP & $\begin{array}{c}\text { HLA-DPA } 1 * 01 / \\
\text { HLA-DPB } 1 * 04: 01\end{array}$ & 214.6 & 8.93 \\
\hline & 213 & 227 & QLSCWVAFGNFKAWV & $\begin{array}{l}\text { HLA-DPA1*01/ } \\
\text { HLA-DPB } 1 * 04: 01\end{array}$ & 216.9 & 8.99 \\
\hline & 216 & 230 & CWVAFGNFKAWVPRP & $\begin{array}{l}\text { HLA-DPA1*01/ } \\
\text { HLA-DPB } 1 * 04: 01\end{array}$ & 269.1 & 10.27 \\
\hline & 215 & 229 & SCWVAFGNFKAWVPR & HLA-DRB $1 * 15: 01$ & 25.4 & 2.18 \\
\hline & 216 & 230 & CWVAFGNFKAWVPRP & HLA-DRB1*15:01 & 28.9 & 2.61 \\
\hline & 214 & 228 & LSCWVAFGNFKAWVP & HLA-DRB1*15:01 & 29 & 2.62 \\
\hline & 217 & 231 & WVAFGNFKAWVPRPP & HLA-DRB1*15:01 & 50 & 5.09 \\
\hline & 218 & 232 & VAFGNFKAWVPRPPP & HLA-DRB1*15:01 & 114 & 11.1 \\
\hline \multirow[t]{3}{*}{ ATMLVAFAP } & 112 & 126 & PNDNPATMLVAFAPP & $\begin{array}{c}\text { HLA-DQA1*03:01/ } \\
\text { DQB1*03:02 }\end{array}$ & 405.1 & 6.83 \\
\hline & 113 & 127 & NDNPATMLVAFAPPG & $\begin{array}{c}\text { HLA-DQA1*03:01/ } \\
\text { DQB } 1 * 03: 02\end{array}$ & 472.4 & 8.16 \\
\hline & 111 & 125 & NPNDNPATMLVAFAP & $\begin{array}{c}\text { HLA-DQA } 1 * 03: 01 / \\
\text { DQB } 1 * 03: 02\end{array}$ & 493.5 & 8.57 \\
\hline ATSTMVSFS & 150 & 164 & SAATSTMVSFSIPYT & $\begin{array}{l}\text { HLA-DQA1*05:01/ } \\
\text { DQB1*03:01 }\end{array}$ & 216.1 & 23.56 \\
\hline \multirow[t]{4}{*}{ DNPATMLVA } & 111 & 125 & NPNDNPATMLVAFAP & $\begin{array}{l}\text { HLA-DQA1*01:02/ } \\
\text { DQB1*06:02 }\end{array}$ & 20.8 & 0.62 \\
\hline & 112 & 126 & PNDNPATMLVAFAPP & $\begin{array}{l}\text { HLA-DQA1*01:02/ } \\
\text { DQB1*06:02 }\end{array}$ & 24.8 & 0.89 \\
\hline & 110 & 124 & SNPNDNPATMLVAFA & $\begin{array}{c}\text { HLA-DQA } 1 * 01: 02 / \\
\text { DQB } 1 * 06: 02\end{array}$ & 25.2 & 0.92 \\
\hline & 113 & 127 & NDNPATMLVAFAPPG & $\begin{array}{c}\text { HLA-DQA } 1 * 01: 02 / \\
\text { DQB } 1 * 06: 02\end{array}$ & 32.1 & 1.43 \\
\hline
\end{tabular}




\begin{tabular}{|c|c|c|c|c|c|c|}
\hline & 109 & 123 & FSNPNDNPATMLVAF & $\begin{array}{c}\text { HLA-DQA1*01:02/ } \\
\text { DQB1*06:02 }\end{array}$ & 44.4 & 2.46 \\
\hline & 114 & 128 & DNPATMLVAFAPPGA & $\begin{array}{l}\text { HLA-DQA } 1 * 01: 02 / \\
\text { DQB } 1 * 06: 02\end{array}$ & 51.6 & 3.09 \\
\hline & 108 & 122 & RFSNPNDNPATMLVA & $\begin{array}{l}\text { HLA-DQA } 1 * 01: 02 / \\
\text { DQB1*06:02 }\end{array}$ & 111.7 & 8.05 \\
\hline \multirow[t]{3}{*}{ DRVYIVRAQ } & 262 & 276 & VDPDDRVYIVRAQRP & $\begin{array}{c}\text { HLA-DQA1*03:01/ } \\
\text { DQB } 1 * 03: 02\end{array}$ & 400.2 & 6.73 \\
\hline & 261 & 275 & DVDPDDRVYIVRAQR & $\begin{array}{l}\text { HLA-DQA } 1 * 03: 01 / \\
\text { DQB1*03:02 }\end{array}$ & 400.5 & 6.74 \\
\hline & 263 & 277 & DPDDRVYIVRAQRPT & $\begin{array}{l}\text { HLA-DQA } 1 * 03: 01 / \\
\text { DQB1*03:02 }\end{array}$ & 469.2 & 8.1 \\
\hline \multirow[t]{9}{*}{ CFTYIAADL } & 92 & 106 & MLSCFTYIAADLRIT & $\begin{array}{l}\text { HLA-DPA1*03:01/ } \\
\text { HLA-DPB } 1 * 04: 02\end{array}$ & 133 & 11.62 \\
\hline & 91 & 105 & AMLSCFTYIAADLRI & $\begin{array}{l}\text { HLA-DPA } 1 * 03: 01 / \\
\text { HLA-DPB } 1 * 04: 02\end{array}$ & 340 & 19.59 \\
\hline & 92 & 106 & MLSCFTYIAADLRIT & HLA-DRB1*09:01 & 67 & 4.54 \\
\hline & 93 & 107 & LSCFTYIAADLRITL & HLA-DRB1*09:01 & 79.4 & 5.46 \\
\hline & 91 & 105 & AMLSCFTYIAADLRI & HLA-DRB1*09:01 & 81.6 & 5.63 \\
\hline & 94 & 108 & SCFTYIAADLRITLR & HLA-DRB1*09:01 & 92.3 & 6.4 \\
\hline & 90 & 104 & AAMLSCFTYIAADLR & HLA-DRB1*09:01 & 103.2 & 7.12 \\
\hline & 95 & 109 & CFTYIAADLRITLRF & HLA-DRB1*09:01 & 123.8 & 8.47 \\
\hline & 89 & 103 & IAAMLSCFTYIAADL & HLA-DRB1*09:01 & 143.6 & 9.71 \\
\hline \multirow[t]{4}{*}{ YMAEVPVSA* } & 137 & 151 & QMLSNFYMAEVPVSA & $\begin{array}{l}\text { HLA-DQA } 1 * 05: 01 / \\
\text { DQB1*02:01 }\end{array}$ & 247 & 5.47 \\
\hline & 138 & 152 & MLSNFYMAEVPVSAA & $\begin{array}{l}\text { HLA-DQA1*05:01/ } \\
\text { DQB1*02:01 }\end{array}$ & 299 & 6.72 \\
\hline & 139 & 153 & LSNFYMAEVPVSAAT & $\begin{array}{l}\text { HLA-DQA1*05:01/ } \\
\text { DQB1*02:01 }\end{array}$ & 393.3 & 8.89 \\
\hline & 140 & 154 & SNFYMAEVPVSAATS & $\begin{array}{l}\text { HLA-DQA } 1 * 05: 01 / \\
\text { DQB1*03:01 }\end{array}$ & 10 & 1.44 \\
\hline
\end{tabular}




\begin{tabular}{|c|c|c|c|c|c|}
\hline 141 & 155 & NFYMAEVPVSAATST & $\begin{array}{c}\text { HLA-DQA1*05:01/ } \\
\text { DQB } 1 * 03: 01\end{array}$ & 10.5 & 1.56 \\
\hline 143 & 157 & YMAEVPVSAATSTMV & $\begin{array}{l}\text { HLA-DQA } 1 * 05: 01 / \\
\text { DQB } 1 * 03: 01\end{array}$ & 10.7 & 1.61 \\
\hline 142 & 156 & FYMAEVPVSAATSTM & $\begin{array}{c}\text { HLA-DQA } 1 * 05: 01 / \\
\text { DQB } 1 * 03: 01\end{array}$ & 10.8 & 1.63 \\
\hline 140 & 154 & SNFYMAEVPVSAATS & HLA-DRB $1 * 01: 01$ & 5.2 & 0.97 \\
\hline 141 & 155 & NFYMAEVPVSAATST & HLA-DRB $1 * 01: 01$ & 6.3 & 1.99 \\
\hline 142 & 156 & FYMAEVPVSAATSTM & HLA-DRB 1*01:01 & 7.8 & 3.36 \\
\hline 143 & 157 & YMAEVPVSAATSTMV & HLA-DRB $1 * 01: 01$ & 13 & 7.34 \\
\hline 140 & 154 & SNFYMAEVPVSAATS & HLA-DRB $1 * 03: 01$ & 385.2 & 12.07 \\
\hline 140 & 154 & SNFYMAEVPVSAATS & HLA-DRB $1 * 04: 01$ & 33.2 & 2.21 \\
\hline 139 & 153 & LSNFYMAEVPVSAAT & HLA-DRB $1 * 04: 01$ & 39.4 & 2.8 \\
\hline 141 & 155 & NFYMAEVPVSAATST & HLA-DRB $1 * 04: 01$ & 47.9 & 3.61 \\
\hline 138 & 152 & MLSNFYMAEVPVSAA & HLA-DRB $1 * 04: 01$ & 50.6 & 3.87 \\
\hline 142 & 156 & FYMAEVPVSAATSTM & HLA-DRB1*04:01 & 65.2 & 5.21 \\
\hline 143 & 157 & YMAEVPVSAATSTMV & HLA-DRB $1 * 04: 01$ & 97.1 & 7.88 \\
\hline 143 & 157 & YMAEVPVSAATSTMV & HLA-DRB $1 * 04: 04$ & 188 & 19.47 \\
\hline 142 & 156 & FYMAEVPVSAATSTM & HLA-DRB1*04:04 & 325.9 & 27.62 \\
\hline 140 & 154 & SNFYMAEVPVSAATS & HLA-DRB1*04:04 & 364.6 & 29.41 \\
\hline 139 & 153 & LSNFYMAEVPVSAAT & HLA-DRB $1 * 08: 02$ & 150.4 & 3.01 \\
\hline 138 & 152 & MLSNFYMAEVPVSAA & HLA-DRB $1 * 08: 02$ & 249.5 & 5.74 \\
\hline 139 & 153 & LSNFYMAEVPVSAAT & HLA-DRB1*09:01 & 20.6 & 0.82 \\
\hline 140 & 154 & SNFYMAEVPVSAATS & HLA-DRB $1 * 09: 01$ & 21.8 & 0.92 \\
\hline 138 & 152 & MLSNFYMAEVPVSAA & HLA-DRB $1 * 09: 01$ & 22.9 & 1.01 \\
\hline 141 & 155 & NFYMAEVPVSAATST & HLA-DRB $1 * 09: 01$ & 34.6 & 1.93 \\
\hline 143 & 157 & YMAEVPVSAATSTMV & HLA-DRB $1 * 09: 01$ & 75.1 & 5.16 \\
\hline 142 & 156 & FYMAEVPVSAATSTM & HLA-DRB $1 * 09: 01$ & 80.2 & 5.53 \\
\hline
\end{tabular}


$140 \quad 154 \quad$ SNFYMAEVPVSAATS

FTYIAADLR* $92 \quad 106$ MLSCFTYIAADLRIT

$93 \quad 107 \quad$ LSCFTYIAADLRITL

$94 \quad 108 \quad$ SCFTYIAADLRITLR

95109 CFTYIAADLRITLRF

$93 \quad 107 \quad$ LSCFTYIAADLRITL

95109 CFTYIAADLRITLRF

$94 \quad 108 \quad$ SCFTYIAADLRITLR

$96 \quad 110 \quad$ FTYIAADLRITLRFS

$92 \quad 106 \quad$ MLSCFTYIAADLRIT

$91 \quad 105 \quad$ AMLSCFTYIAADLRI

90104 AAMLSCFTYIAADLR

$96 \quad 110 \quad$ FTYIAADLRITLRFS

95109 CFTYIAADLRITLRF

$93 \quad 107 \quad$ LSCFTYIAADLRITL

$92 \quad 106 \quad$ MLSCFTYIAADLRIT

$91 \quad 105 \quad$ AMLSCFTYIAADLRI

$90 \quad 104$ AAMLSCFTYIAADLR
HLA-DRB3*01:01

$499.8 \quad 11.74$

HLA-DPA $1 * 01: 03 /$

HLA-DPB $1 * 02: 01$

$280.2 \quad 15.66$

HLA-DPA $1 * 01: 03 /$

HLA-DPB $1 * 02: 01$

$313.8 \quad 16.69$

HLA-DPA $1 * 01: 03 /$

HLA-DPB $1 * 02: 01$

$377.1 \quad 18.48$

HLA-DPA $1 * 01: 03 /$

HLA-DPB $1 * 02: 01$

$398.7 \quad 19.05$

HLA-DPA $1 * 02: 01 /$

HLA-DPB $1 * 01: 01$

$121.4 \quad 12.21$

HLA-DPA $1 * 02: 01 /$

HLA-DPB $1 * 01: 01$

$122.5 \quad 12.3$

HLA-DPA $1 * 02: 01 /$

HLA-DPB $1 * 01: 01$

$124.3 \quad 12.46$

HLA-DPA $1 * 02: 01 /$

HLA-DPB $1 * 01: 01$

$136.8 \quad 13.42$

HLA-DPA $1 * 02: 01 /$

HLA-DPB $1 * 01: 01$

$159.5 \quad 15.08$

HLA-DPA $1 * 02: 01 /$

HLA-DPB $1 * 01: 01$

$192.2 \quad 17.25$

HLA-DPA $1 * 02: 01 /$

HLA-DPB $1 * 01: 01$

$257.2 \quad 20.96$

HLA-DPA $1 * 02: 01 /$

HLA-DPB $1 * 05: 01 \quad 365.4 \quad 7.9$

HLA-DPA1 $* 02: 01 /$

HLA-DPB1*05:01 $367 \quad 7.93$

HLA-DRB $1 * 01: 01 \quad 10.2 \quad 5.34$

HLA-DRB $1 * 01: 01 \quad 14.4 \quad 8.24$

HLA-DRB $1 * 01: 01 \quad 19.4 \quad 11$

HLA-DRB $1 * 01: 01 \quad 27.9 \quad 14.68$ 


\begin{tabular}{|c|c|c|c|c|c|}
\hline 92 & 106 & MLSCFTYIAADLRIT & HLA-DRB1*03:01 & 211.6 & 8.31 \\
\hline 91 & 105 & AMLSCFTYIAADLRI & HLA-DRB1*03:01 & 352.9 & 11.43 \\
\hline 93 & 107 & LSCFTYIAADLRITL & HLA-DRB1*04:01 & 128.7 & 10.29 \\
\hline 94 & 108 & SCFTYIAADLRITLR & HLA-DRB1*04:01 & 137.8 & 10.94 \\
\hline 95 & 109 & CFTYIAADLRITLRF & HLA-DRB1*04:01 & 153.2 & 12.01 \\
\hline 96 & 110 & FTYIAADLRITLRFS & HLA-DRB1*04:01 & 162.8 & 12.66 \\
\hline 92 & 106 & MLSCFTYIAADLRIT & HLA-DRB1*04:01 & 176.2 & 13.51 \\
\hline 91 & 105 & AMLSCFTYIAADLRI & HLA-DRB1*04:01 & 222 & 16.28 \\
\hline 90 & 104 & AAMLSCFTYIAADLR & HLA-DRB1*04:01 & 323.6 & 21.54 \\
\hline 91 & 105 & AMLSCFTYIAADLRI & HLA-DRB1*04:04 & 43 & 4.7 \\
\hline 90 & 104 & AAMLSCFTYIAADLR & HLA-DRB1*04:04 & 44.2 & 4.86 \\
\hline 93 & 107 & LSCFTYIAADLRITL & HLA-DRB1*04:04 & 67 & 8.03 \\
\hline 92 & 106 & MLSCFTYIAADLRIT & HLA-DRB1*04:04 & 67.8 & 8.13 \\
\hline 95 & 109 & CFTYIAADLRITLRF & HLA-DRB1*04:04 & 353.1 & 28.92 \\
\hline 96 & 110 & FTYIAADLRITLRFS & HLA-DRB1*04:04 & 497.9 & 34.63 \\
\hline 93 & 107 & LSCFTYIAADLRITL & HLA-DRB1*04:05 & 55.8 & 5.48 \\
\hline 91 & 105 & AMLSCFTYIAADLRI & HLA-DRB1*04:05 & 56.5 & 5.56 \\
\hline 92 & 106 & MLSCFTYIAADLRIT & HLA-DRB1*04:05 & 60.5 & 5.97 \\
\hline 94 & 108 & SCFTYIAADLRITLR & HLA-DRB1*04:05 & 72.6 & 7.15 \\
\hline 95 & 109 & CFTYIAADLRITLRF & HLA-DRB1*04:05 & 129.5 & 11.95 \\
\hline 96 & 110 & FTYIAADLRITLRFS & HLA-DRB1*04:05 & 220.6 & 17.73 \\
\hline 93 & 107 & LSCFTYIAADLRITL & HLA-DRB1*07:01 & 28.9 & 5.51 \\
\hline 91 & 105 & AMLSCFTYIAADLRI & HLA-DRB1*07:01 & 32.3 & 6.09 \\
\hline 92 & 106 & MLSCFTYIAADLRIT & HLA-DRB1*07:01 & 36 & 6.62 \\
\hline 94 & 108 & SCFTYIAADLRITLR & HLA-DRB1*07:01 & 39.3 & 7.09 \\
\hline 90 & 104 & AAMLSCFTYIAADLR & HLA-DRB1*07:01 & 65 & 10.55 \\
\hline
\end{tabular}




\begin{tabular}{|c|c|c|c|c|c|}
\hline 92 & 106 & MLSCFTYIAADLRIT & HLA-DRB1 $* 15: 01$ & 401.3 & 25.89 \\
\hline 91 & 105 & AMLSCFTYIAADLRI & HLA-DRB 1*15:01 & 412.2 & 26.26 \\
\hline 94 & 108 & SCFTYIAADLRITLR & HLA-DRB4*01:01 & 252.5 & 17.14 \\
\hline 93 & 107 & LSCFTYIAADLRITL & HLA-DRB4*01:01 & 308.6 & 19.86 \\
\hline 95 & 109 & CFTYIAADLRITLRF & HLA-DRB4*01:01 & 320.3 & 20.38 \\
\hline 96 & 110 & FTYIAADLRITLRFS & HLA-DRB4*01:01 & 340.7 & 21.29 \\
\hline 92 & 106 & MLSCFTYIAADLRIT & HLA-DRB4*01:01 & 391.3 & 23.4 \\
\hline 91 & 105 & AMLSCFTYIAADLRI & HLA-DRB4*01:01 & 423.8 & 24.65 \\
\hline 93 & 107 & LSCFTYIAADLRITL & HLA-DRB5*01:01 & 3.4 & 0.37 \\
\hline 92 & 106 & MLSCFTYIAADLRIT & HLA-DRB5*01:01 & 4.2 & 0.6 \\
\hline 94 & 108 & SCFTYIAADLRITLR & HLA-DRB5*01:01 & 4.2 & 0.6 \\
\hline 91 & 105 & AMLSCFTYIAADLRI & HLA-DRB5*01:01 & 4.8 & 0.78 \\
\hline 95 & 109 & CFTYIAADLRITLRF & HLA-DRB5*01:01 & 5.6 & 1.04 \\
\hline 90 & 104 & AAMLSCFTYIAADLR & HLA-DRB5*01:01 & 6.6 & 1.34 \\
\hline 96 & 110 & FTYIAADLRITLRFS & HLA-DRB5*01:01 & 8.1 & 1.8 \\
\hline 91 & 105 & AMLSCFTYIAADLRI & $\begin{array}{l}\text { HLA-DQA } 1 * 05: 01 / \\
\text { DQB } 1 * 02: 01\end{array}$ & 119.5 & 2.24 \\
\hline 90 & 104 & AAMLSCFTYIAADLR & $\begin{array}{l}\text { HLA-DQA1*05:01/ } \\
\text { DQB1*02:01 }\end{array}$ & 132.4 & 2.58 \\
\hline 92 & 106 & MLSCFTYIAADLRIT & $\begin{array}{l}\text { HLA-DQA } 1 * 05: 01 / \\
\text { DQB } 1 * 02: 01\end{array}$ & 151.7 & 3.09 \\
\hline 93 & 107 & LSCFTYIAADLRITL & $\begin{array}{l}\text { HLA-DQA } 1 * 05: 01 / \\
\text { DQB1*02:01 }\end{array}$ & 167.8 & 3.5 \\
\hline 94 & 108 & SCFTYIAADLRITLR & $\begin{array}{l}\text { HLA-DQA } 1 * 05: 01 / \\
\text { DQB } 1 * 02: 01\end{array}$ & 203.6 & 4.4 \\
\hline 95 & 109 & CFTYIAADLRITLRF & $\begin{array}{l}\text { HLA-DQA1*05:01/ } \\
\text { DQB1*02:01 }\end{array}$ & 223.7 & 4.9 \\
\hline 96 & 110 & FTYIAADLRITLRFS & $\begin{array}{c}\text { HLA-DQA } 1 * 05: 01 / \\
\text { DQB } 1 * 02: 01\end{array}$ & 294 & 6.61 \\
\hline
\end{tabular}




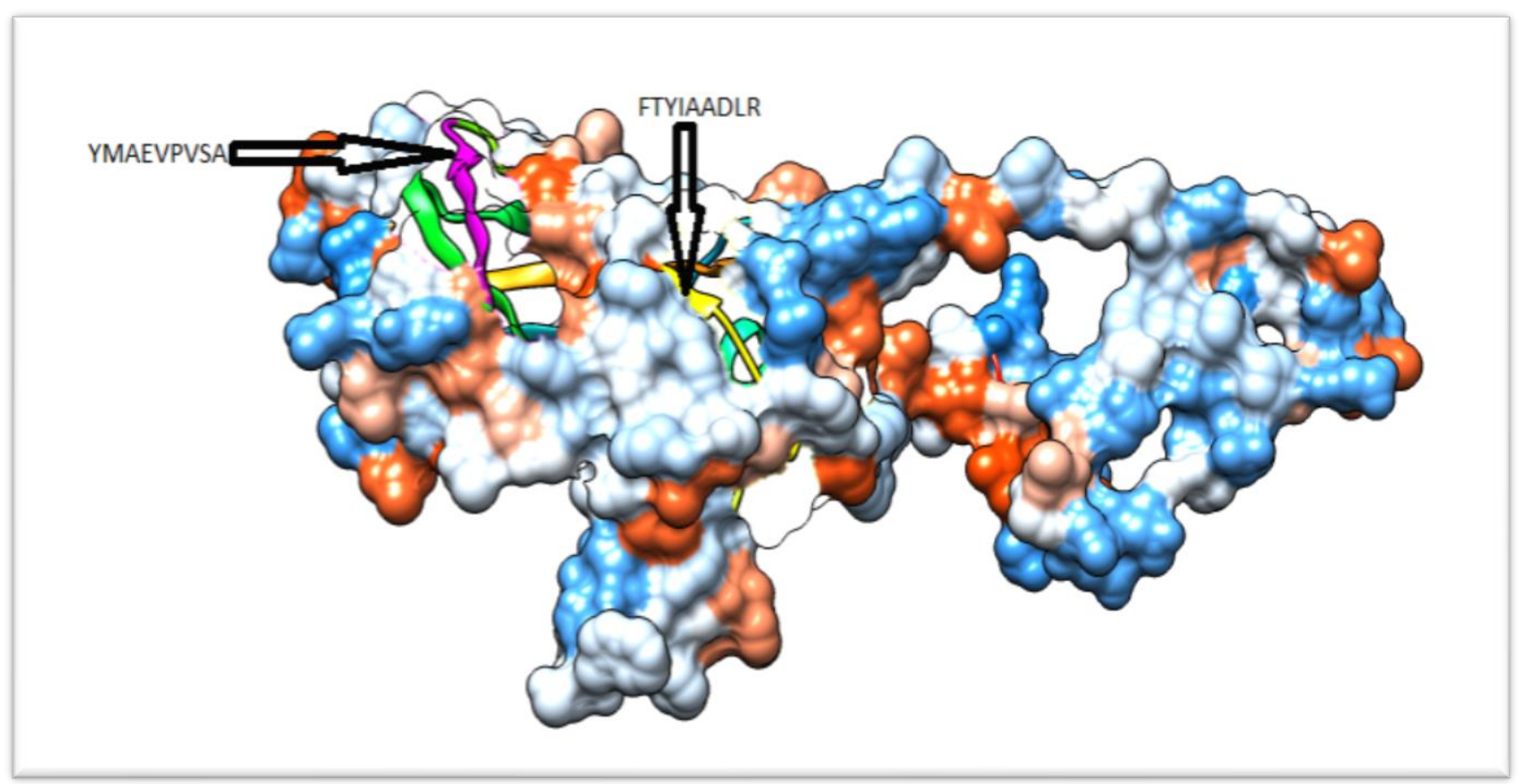

Figure (10): 3D structure of T cell top epitopes interacts with MCH1, using chimera

Table (5): results of population coverage of all peptides in both MHC I and MHC II in the world:

\begin{tabular}{|c|c|c|c|c|c|}
\hline \multirow[t]{2}{*}{ Epitope } & $\begin{array}{c}\text { World } \\
\text { Coverage }\end{array}$ & $\begin{array}{c}\text { Total HLA } \\
\text { Hits }\end{array}$ & Epitope & $\begin{array}{c}\text { World } \\
\text { Coverage }\end{array}$ & $\begin{array}{c}\text { Total HLA } \\
\text { Hits }\end{array}$ \\
\hline & MHC1 & & & MHC11 & \\
\hline $\begin{array}{c}\text { Epitope \#1: } \\
\text { KLENFFSFY }\end{array}$ & $49.80 \%$ & 5 & $\begin{array}{c}\text { Epitope \#1: } \\
\text { AADLRITL } \\
\mathbf{R}\end{array}$ & $11.53 \%$ & 1 \\
\hline $\begin{array}{c}\text { Epitope \#2: } \\
\text { AATSTMVSF }\end{array}$ & $26.14 \%$ & 4 & $\begin{array}{c}\text { Epitope \#2: } \\
\text { AFGNFKA } \\
\text { WV }\end{array}$ & $43.96 \%$ & 3 \\
\hline $\begin{array}{c}\text { Epitope \#3: } \\
\text { AEVPVSAAT }\end{array}$ & $13.63 \%$ & 2 & $\begin{array}{c}\text { Epitope \#3: } \\
\text { ATMLVAF } \\
\text { AP }\end{array}$ & $40.19 \%$ & 2 \\
\hline $\begin{array}{c}\text { Epitope \#4: } \\
\text { AFAPPGATI }\end{array}$ & $8.12 \%$ & 1 & $\begin{array}{c}\text { Epitope \#4: } \\
\text { ATSTMVSF } \\
\text { S }\end{array}$ & $56.45 \%$ & 2 \\
\hline
\end{tabular}




\begin{tabular}{|c|c|c|c|c|}
\hline $\begin{array}{c}\text { Epitope \#5: } \\
\text { DTGNIENGA }\end{array}$ & $2.50 \%$ & 1 & $\begin{array}{c}\text { Epitope \#5: } \\
\text { DNPATML } \\
\text { VA }\end{array}$ & $34.55 \%$ \\
\hline $\begin{array}{c}\text { Epitope \#6: } \\
\text { ENFFSFYRL }\end{array}$ & $2.50 \%$ & 1 & $\begin{array}{c}\text { Epitope \#6: } \\
\text { DRVYIVRA } \\
\text { Q }\end{array}$ & $40.19 \%$ \\
\hline $\begin{array}{l}\text { Epitope \#7: } \\
\text { FAPPGATIP }\end{array}$ & $17.99 \%$ & 2 & $\begin{array}{c}\text { Epitope \#7: } \\
\text { CFTYIAAD } \\
\text { L }\end{array}$ & $32.12 \%$ \\
\hline $\begin{array}{l}\text { Epitope \#8: } \\
\text { FSIPYTSPL }\end{array}$ & $75.41 \%$ & 13 & $\begin{array}{c}\text { Epitope \#8: } \\
\text { CWVAFGN } \\
\text { FK }\end{array}$ & $63.19 \%$ \\
\hline $\begin{array}{l}\text { Epitope \#9: } \\
\text { FTYIAADLR }\end{array}$ & $25.64 \%$ & 3 & $\begin{array}{c}\text { Epitope \#9: } \\
\text { EVPVSAAT } \\
\text { S }\end{array}$ & $11.53 \%$ \\
\hline $\begin{array}{c}\text { Epitope \#10: } \\
\text { FYMAEVPVS }\end{array}$ & $3.04 \%$ & 1 & $\begin{array}{c}\text { Epitope \#10: } \\
\text { ENFFSFYR } \\
\text { L }\end{array}$ & $83.57 \%$ \\
\hline $\begin{array}{l}\text { Epitope \#11: } \\
\text { GAPSLSFPA }\end{array}$ & $1.95 \%$ & 1 & $\begin{array}{c}\text { Epitope \#11: } \\
\text { FAPPGATI } \\
\text { P }\end{array}$ & $56.45 \%$ \\
\hline $\begin{array}{c}\text { Epitope \#12: } \\
\text { GNFKAWVPR }\end{array}$ & $11.03 \%$ & 2 & $\begin{array}{c}\text { Epitope \#12: } \\
\text { FGNFKAW } \\
\text { VP }\end{array}$ & $64.39 \%$ \\
\hline $\begin{array}{l}\text { Epitope \#13: } \\
\text { IPYTSPLSA }\end{array}$ & $20.62 \%$ & 2 & $\begin{array}{c}\text { Epitope \#13: } \\
\text { FGQLSSGS } \\
\text { W }\end{array}$ & $36.62 \%$ \\
\hline $\begin{array}{c}\text { Epitope \#14: } \\
\text { IVRAQRPTY }\end{array}$ & $24.86 \%$ & 5 & $\begin{array}{l}\text { Epitope \#14: } \\
\text { FSIPYTSPL }\end{array}$ & $48.84 \%$ \\
\hline $\begin{array}{l}\text { Epitope \#15: } \\
\text { LENFFSFYR }\end{array}$ & $11.03 \%$ & 2 & $\begin{array}{c}\text { Epitope \#15: } \\
\text { FTYIAADL } \\
\text { R }\end{array}$ & $98.69 \%$ \\
\hline $\begin{array}{l}\text { Epitope \#16: } \\
\text { LSAIPTSYF }\end{array}$ & $22.02 \%$ & 4 & $\begin{array}{c}\text { Epitope \#16: } \\
\text { FYMAEVP } \\
\text { VS }\end{array}$ & $82.35 \%$ \\
\hline
\end{tabular}




\author{
Epitope \#17: \\ LVAFAPPGA
}

Epitope \#18:

$42.53 \%$

MLSCFTYIA

$\begin{array}{cc}\text { Epitope \#19: } & 40.60 \% \\ \text { MLVAFAPPG } & \\ \text { Epitope \#20: } & 42.53 \% \\ \text { MVSFSIPYT } & \end{array}$

Epitope \#21:

NDNPATMLV

Epitope \#22:

NPATMLVAF

Epitope \#23:

NPLPPDTKL

Epitope \#24:

$31.35 \%$

NPNDNPATM

Epitope \#25:

PLSAIPTSY

Epitope \#26:

PNDNPATML

Epitope \#27:

PYTSPLSAI

Epitope \#28:

$43.03 \%$

RVYIVRAQR

$7.85 \%$
1

Epitope \#17:

$67.20 \%$

5

KLENFFSF

$\mathbf{Y}$

3

Epitope \#18: $\quad 56.45 \%$

2

GAPSLSFP

A

$2 \quad$ Epitope \#19:

$2.33 \%$

1

IPYTSPLSA

3

Epitope \#20:

$27.97 \%$

2

IVRAQRPT

Y

Epitope \#21: $\quad 71.33 \%$

8

LENFFSFY

R

4

Epitope \#22: $\quad 38.32 \%$

5

LSAIPTSYF

1

Epitope \#23: $\quad 34.18 \%$

3

LVAFAPPG

A

5

Epitope \#24: $\quad 36.07 \%$

3

MAEVPVS

AA

Epitope \#25: $\quad 11.53 \%$

1

MLSCFTYI

A

1

Epitope \#26: $\quad 78.90 \%$

8

MLVAFAPP

G

1

Epitope \#27:

$31.32 \%$

2

MLSCFTYI

A

5

Epitope \#28:

$54.25 \%$

6
MVSFSIPY 


\begin{tabular}{|c|c|c|c|c|}
\hline $\begin{array}{l}\text { Epitope \#29: } \\
\text { TKLENFFSF }\end{array}$ & $27.86 \%$ & 3 & $\begin{array}{c}\text { Epitope \#29: } \\
\text { NFGQLSSG } \\
\text { S }\end{array}$ & $56.45 \%$ \\
\hline $\begin{array}{l}\text { Epitope \#30: } \\
\text { TMLVAFAPP }\end{array}$ & $1.95 \%$ & 1 & $\begin{array}{c}\text { Epitope \#30: } \\
\text { NFFSFYRL } \\
\text { L }\end{array}$ & $43.67 \%$ \\
\hline $\begin{array}{l}\text { Epitope \#31: } \\
\text { TMVSFSIPY }\end{array}$ & $59.39 \%$ & 10 & $\begin{array}{l}\text { Epitope \#31: } \\
\text { PLSAIPTSY }\end{array}$ & $56.45 \%$ \\
\hline $\begin{array}{l}\text { Epitope \#32: } \\
\text { TSTMVSFSI }\end{array}$ & $10.00 \%$ & 3 & $\begin{array}{c}\text { Epitope \#32: } \\
\text { PNDNPAT } \\
\text { ML }\end{array}$ & $11.53 \%$ \\
\hline $\begin{array}{c}\text { Epitope \#33: } \\
\text { TSYFGWEDW }\end{array}$ & $7.26 \%$ & 2 & $\begin{array}{l}\text { Epitope \#33: } \\
\text { PYTSPLSAI }\end{array}$ & $56.45 \%$ \\
\hline $\begin{array}{l}\text { Epitope \#34: } \\
\text { TYIAADLRI }\end{array}$ & $28.43 \%$ & 3 & $\begin{array}{c}\text { Epitope \#34: } \\
\text { QLSCWVA } \\
\text { FG }\end{array}$ & $34.55 \%$ \\
\hline $\begin{array}{l}\text { Epitope \#35: } \\
\text { VAFAPPGAT }\end{array}$ & $17.99 \%$ & 2 & $\begin{array}{c}\text { Epitope \#35: } \\
\text { RVYIVRAQ } \\
\text { R }\end{array}$ & $29.87 \%$ \\
\hline $\begin{array}{c}\text { Epitope \#36: } \\
\text { VAFGNFKAW }\end{array}$ & $25.94 \%$ & 5 & $\begin{array}{c}\text { Epitope \#36: } \\
\text { SAATSTMV } \\
\text { S }\end{array}$ & $34.55 \%$ \\
\hline $\begin{array}{l}\text { Epitope \#37: } \\
\text { VPVSAATST }\end{array}$ & $12.78 \%$ & 1 & $\begin{array}{c}\text { Epitope \#37: } \\
\text { SCFTYIAA } \\
\text { D }\end{array}$ & $51.32 \%$ \\
\hline $\begin{array}{c}\text { Epitope \#38: } \\
\text { VSAATSTMV }\end{array}$ & $6.81 \%$ & 2 & $\begin{array}{l}\text { Epitope \#38: } \\
\text { SIPYTSPLS }\end{array}$ & $28.50 \%$ \\
\hline $\begin{array}{c}\text { Epitope \#39: } \\
\text { WVAFGNFKA }\end{array}$ & $4.43 \%$ & 2 & $\begin{array}{l}\text { Epitope \#39: } \\
\text { SPLSAIPTS }\end{array}$ & $4.77 \%$ \\
\hline $\begin{array}{c}\text { Epitope \#40: } \\
\text { YMAEVPVSA }\end{array}$ & $52.81 \%$ & 5 & $\begin{array}{c}\text { Epitope \#40: } \\
\text { SYFGWED } \\
\text { WS }\end{array}$ & $31.46 \%$ \\
\hline Total & 88.9 & 116 & $\begin{array}{c}\text { Epitope \#41: } \\
\text { TKLENFFS } \\
\text { F }\end{array}$ & $76.04 \%$ \\
\hline
\end{tabular}




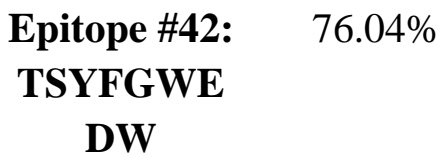

Epitope \#43:

$4.77 \%$

TMLVAFA

PP

Epitope \#44:

$47.34 \%$

4

TMVSFSIP

Y

Epitope \#45:

$11.53 \%$

1

TSPLSAIPT

Epitope \#46:

$11.53 \%$

1

Epitope \#47:

$63.26 \%$

4

TYIAADLR

I

Epitope \#48:

$61.47 \%$

4

$\mathrm{T}$

Epitope \#49: $\quad 89.56 \%$

4

VAFGNFK

AW

Epitope \#50:

$78.39 \%$

6

VPVSAATS

T

Epitope \#51:

$72.43 \%$

7

VYIVRAQR

$\mathbf{P}$

Epitope \#52:

$42.73 \%$

6

WVAFGNF

KA

Epitope \#53: $\quad 39.02 \%$

YFGWEDW

SG 


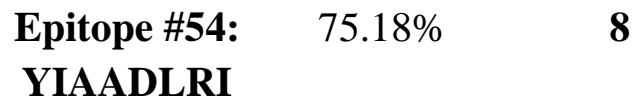

$\mathbf{T}$
Epitope \#55: $\quad 83.66 \%$
YMAEVPV

SA

Epitope \#56:

$17.24 \%$

2

YTSPLSAIP

Total

99.99

206

Table (6): population coverage of top epitopes in both MHC I and MHC II in the world:

\begin{tabular}{|c|c|c|c|c|c|}
\hline \multirow{2}{*}{ Epitope } & Coverage & \multirow{2}{*}{$\begin{array}{c}\text { Total HLA } \\
\text { hits }\end{array}$} & \multirow{2}{*}{ Epitope } & Coverage & \multirow{2}{*}{ Total HLA hits } \\
\hline & Class I & & & class II & \\
\hline FSIPYTSPL & $75.41 \%$ & 13 & FTYIAADLR & $98.69 \%$ & 16 \\
\hline TMVSFSIPY & $59.39 \%$ & 10 & LSAIPTSYF & $85.22 \%$ & 8 \\
\hline YMAEVPVSA & $52.81 \%$ & 5 & YMAEVPVSA & $83.66 \%$ & 10 \\
\hline
\end{tabular}

\section{Discussion:}

In the current study, an immunoinformatic-driven approach used to screen emergent immunogen against Aichi virus. B-cell immunity is given the priority to design vaccine but T-cell was also shown to induce strong immune response (36) According to the prediction result of IEDB the peptides (PLPPDT, PPLPTP, and LPPLPTP) were passed Bepipred linear epitope prediction test, Emini surface accessibility test and Kolaskar and Tongaonkar antigenicity test, there were 14 conserved epitopes that have the binding affinity to B cell while there are 17 epitopes from different windows size was predicted to be on the surface and antigenic according to Emini surface accessibility and Tongaonkar antigenicity test. According to $\mathrm{T}$ cell, epitopes are typically peptide 
fragments and their responses are exquisitely antigen-specific, and they are important as antibodies in defending against infection $(37,38)$.

T cell immune response is long-lasting immunity as foreign particles and can avoid the effect of memory produced via an immune system. In the prediction results of IEDB, the peptides that have good affinity with HLA molecules were FSIPYTSPL and TMVSFSIPY for MHC1. FTYIAADLR and YMAEVPVSA for MHC class II.

We installed threshold associated with all epitopes in both MHC1 and MHC11 by reformulating the peptides bind with an IC50 value below $500 \mathrm{nM}$, this allowed computing the number of true negatives, true positives, false negatives, and false positives.

MHC1 binding prediction was analyzed using IEDB Based on Artificial neural network (ANN) with half-maximal inhibitory concentration (IC50) $\leq 500 ; 41$ conserved peptides were predicted to interact with different MHC-1 alleles. The peptide FSIPYTSPL from 159 to 167 had higher affinity to interact with 13 alleles (HLAA*02:01, HLA-A*02:06, HLA-A*68:02, HLA-B*15:01, HLA-B*35:01, HLAB*39:01, HLA-B*46:01, HLA-B*58:01, HLA-C*03:03, HLA-C*07:02, HLAC*12:03, HLA-C*14:02, HLA-C*15:02), followed by TMVSFSIPY from155 to 163 that binds 10 alleles (HLA-A*03:01, HLA-A*11:01, HLA-A*29:02, HLA-A*30:02, HLA-A*32:01, HLA-A*68:01, HLA-B*15:01, HLA-B*15:02, HLA-B*35:01, HLA$\left.C^{*} 12: 03\right)$. World population coverage results for total epitopes binding to MHC1 alleles was $98.9 \%$ and for the most promising peptides (FSIPYTSPL, TMVSFSIPY) was $75.41 \%$ and $59.39 \%$ respectively. these epitopes would possibly be the best vaccine candidates primarily based on the fact that an epitope needs to be as conservative as possible to provide extensive protection among specific virus isolates. These epitopes were also identified as nontoxic to humans depend on the antigenicity test. All the predicted epitopes were placed on the surface of the viral protein 1, representing the accessibility for the entered virus.

MHC II binding prediction was also analyzed based on Artificial neural network (NNalign) with half-maximal inhibitory concentration (IC50) $\leq 500.54$ conserved epitopes found to interact with MHC-II alleles. The most promising peptides was FTYIAADLR from 96 to 104 with 9-mers which interact with 16 alleles (HLA-DRB5*01:01, HLADRB4*01:01, HLA-DRB1*15:01, HLA-DRB1*07:01, HLA-DRB1*04:05, HLA- 
DRB1*04:04, HLA-DRB1*04:01, HLA-DRB1*03:01, HLA-DRB1*01:01, HLADQA1*05:01, HLA-DQB1*02:01, HLA-DPA1*02:01, HLA-DPB1*05:01, HLADPA1*02:01, HLA-DPB1*01:01, HLA-DPA1*01:03, HLA-DPB1*02:01) followed by YMAEVPVSA from (143) to (151) which interact with 10 alleles (HLADRB1*09:01, HLA-DRB1*08:02, HLA-DRB1*04:04, HLA-DRB1*04:01, HLADRB1*03:01, HLA-DRB1*01:01, HLA-DQA1*05:01, HLA-DQB1*03:01, HLADQA1*05:01, HLA-DQB1*02:01). The world population coverage results for all epitopes that have binding affinity to MHC11 alleles was $99.99 \%$ while world population coverage of the most promising three epitopes FTYIAADLR and YMAEVPVSA was $98.69 \%$ and $83.66 \%$ respectively.

An overarching approach to gain most protection against viral infections is to design a successful peptide-based vaccine following the identification of essential epitopes by using the immunoinformatic approach combined with an effective adjuvant choice. Computational immunology is now regarded to contribute to vaccine design in the way of computational chemistry contributes to drug design, before the wet lab confirmation, an advance bioinformatics software should be employed to predict these properties $(37,39)$.

Immunoinformatic focuses mostly on small peptides ranging from 8 to 11 residues, just one epitope per protein can be sufficient to create an immune response in the host $(40-$ 42). Bioinformatic techniques to search for epitopes are well understood and available, however can sometimes lead to high false positive rates(43). Despite this drawback, epitope predictors are successful of identifying weak or even strong epitope motifs that have been experimentally ignored (44).

With the advent of next-generation sequencing (NGS) methods, an extraordinary wealth of information has become available that requires moreadvanced immunoinformatic tools. this has allowed new opportunities for translational applications of epitope prediction, such as epitope-based design of prophylactic and therapeutic vaccines (45).

\section{Conclusion:}

World population coverage results for total epitopes binding for both MHC1 and 11 alleles was $99.8 \%$ and the most promising T-cell peptides was FSIPYTSPL from 159 
to 167 that considered as a unique domain which successfully interacted with both MHC1 and MHC11 alleles together, and it can be binding with 19 distinctive alleles and provided the highest population coverage epitope set $(87.42 \%)$ this region is probably promising and This peptide should be considered as a viable peptide vaccine for Aichi virus.

\section{Recommendation:}

We recommend Further in vitro and in vivo studies to undertake the effectiveness of these predicted epitopes as peptide vaccine. and also, to do further studies in other strains, there will be a possibility to find common conserved promising epitopes for multiple strains. this work considered for further investigation.

\section{Acknowledgment:}

This research was supported by Africa city of technology, for whom the authors would like to show their gratitude for their provided insight and expertise that greatly assisted the research.

\section{Confect of interest:}

the authors declare that there is no conflict of interest regarding the publication of this paper and the authors declare that they have no competing interests.

\section{Data availability:}

All relevant data used to support the findings of this study are included within the manuscript and supplementary information files.

\section{References:}

.1 Yamashita T, Sakae K, Kobayashi S, Ishihara Y, Miyake T, Mubina A, et al. Isolation of cytopathic small round virus (Aichi virus) from Pakistani children and Japanese travelers from Southeast Asia. Microbiology and immunology. 1995;39(6):433-5.

.2 Kitajima M, Gerba C. Aichi virus 1: environmental occurrence and behavior. Pathogens. 2015;4(2):256-68.

.3 Ambert-Balay K, Lorrot M, Bon F, Giraudon H, Kaplon J, Wolfer M, et al. Prevalence and genetic diversity of Aichi virus strains in stool samples from community and hospitalized patients. Journal of clinical microbiology. 2008;46(4):1252-8.

.4 Kaikkonen S, Räsänen S, Rämet M, Vesikari TJE, Infection. Aichi virus infection in children with acute gastroenteritis in Finland. 2010;138(8):1166-71. .5 Yamashita T, Sugiyama M, Tsuzuki H, Sakae K, Suzuki Y, Miyazaki Y. Application of a reverse transcription-PCR for identification and differentiation of 
Aichi virus, a new member of the Picornavirus family associated with gastroenteritis in humans. Journal of Clinical Microbiology. 2000;38(8):2955-61.

.6 Oh D-Y, Silva P, Hauroeder B, Diedrich S, Cardoso D, Schreier E. Molecular characterization of the first Aichi viruses isolated in Europe and in South America. Archives of virology. 2006;151(6):1199-206.

.7 Pham NTK, Khamrin P, Nguyen TA, Kanti DS, Phan TG, Okitsu S, et al. Isolation and molecular characterization of Aichi viruses from fecal specimens collected in Japan, Bangladesh, Thailand, and Vietnam. Journal of clinical microbiology. 2007;45(7):2287-8.

.8 Sdiri-Loulizi K, Gharbi-Khélifi H, De Rougemont A, Chouchane S, Sakly N, Ambert-Balay K, et al. Acute infantile gastroenteritis associated with human enteric viruses in Tunisia. 2008;46(4):1349-55.

.9 Terio V, Bottaro M, Di Pinto A, Fusco G, Barresi T, Tantillo G, et al. Occurrence of Aichi virus in retail shellfish in Italy. Food Microbiology. 2018;74:120-4.

.10 Yamashita T, Sakae K, Tsuzuki H, Suzuki Y, Ishikawa N, Takeda N, et al. Complete nucleotide sequence and genetic organization of aichi virus, a distinct member of the picornaviridaeassociated with acute gastroenteritis in humans. Journal of virology. 1998;72(10):8408-12.

.11 Sabin C, Füzik T, Škubník K, Pálková L, Lindberg AM, Plevka PJJov. Structure of Aichi virus 1 and its empty particle: clues towards kobuvirus genome release mechanism. 2016:JVI. 01601-16.

.12 Zhu L, Wang X, Ren J, Kotecha A, Walter TS, Yuan S, et al. Structure of human Aichi virus and implications for receptor binding. Nature microbiology. 2016;1(11):16150.

.13 Li W, Joshi M, Singhania S, Ramsey K, Murthy AJV. Peptide vaccine: progress and challenges. 2014;2(3):515-36.

.14 Lo Y-T, Pai T-W, Wu W-K, Chang H-TJBb. Prediction of conformational epitopes with the use of a knowledge-based energy function and geometrically related neighboring residue characteristics. 2013;14(4):S3.

.15 Reche PA, Fernandez-Caldas E, Flower DR, Fridkis-Hareli M, Hoshino YJJoir. Peptide-based immunotherapeutics and vaccines. 2014;2014.

.16 Purcell AW, McCluskey J, Rossjohn JJNrDd. More than one reason to rethink the use of peptides in vaccine design. 2007;6(5):404.

.17 Badawi MM, Fadl Alla A, Alam SS, Mohamed WA, Osman D, Alrazig Ali S, et al. Immunoinformatics predication and in silico modeling of epitope-based peptide vaccine against virulent Newcastle disease viruses. 2016;4(3):61-71.

.18 Abu-haraz A, Abd-elrahman KA, Ibrahim MS, Hussien WH, Mohammed MS, Badawi MM, et al. Multi epitope peptide vaccine prediction against Sudan Ebola virus using immuno-informatics approaches. 2017;5(203):2379-1764.1000203.

.19 Awad-Elkareem M, Osman S, Mohamed H, Hassan H, Abu-haraz AJIR. Prediction and Conservancy Analysis of Multiepitope Based Peptide Vaccine Against Merkel Cell Polyomavirus: An Immunoinformatics Approach. 2017;13(134):2.

.20 Abdelbagi M, Hassan T, Shihabeldin M, Bashir S, Ahmed EJIR. Immunoinformatics Prediction of Peptide-Based Vaccine Against African Horse Sickness Virus. 2017;13(135):2.

.21 Idris S, Salih S, Basheir M, Elhadi A, Kamel S, Abd-elrahman K, et al. In silico Prediction of Peptide based Vaccine against Fowlpox Virus (FPV).

2018;14(2):1-11. 
.22 Ahmed O, Abdelhalim A, Obi S, Elrahman K, Hamdi AJIR.

Immunoinformatic approach for epitope-based peptide vaccine against Lagos rabies virus glycoprotein G. 2017;13(137):2.

.23 Kumar S, Stecher G, Tamura K. MEGA7: Molecular Evolutionary Genetics Analysis Version 7.0 for Bigger Datasets. Mol Biol Evol. 2016;33(7):1870-4.

.24 Hall TA, editor BioEdit: a user-friendly biological sequence alignment editor and analysis program for Windows 95/98/NT. Nucleic acids symposium series; 1999: [London]: Information Retrieval Ltd., c1979-c2000.

.25 Vita R, Overton JA, Greenbaum JA, Ponomarenko J, Clark JD, Cantrell JR, et al. The immune epitope database (IEDB) 3.0. Nucleic acids research. 2014;43(D1):D405-D12.

.26 Vita R, Mahajan S, Overton JA, Dhanda SK, Martini S, Cantrell JR, et al. The Immune Epitope Database (IEDB): 2018 update. Nucleic acids research. 2018;47(D1):D339-D43.

.27 Hasan A, Hossain M, Alam J. A computational assay to design an epitopebased Peptide vaccine against Saint Louis encephalitis virus. Bioinformatics and Biology insights. 2013;7:BBI. S13402.

.28 Larsen JEP, Lund O, Nielsen M. Improved method for predicting linear B-cell epitopes. Immunome research. 2006;2(1):2.

.29 Emini EA, Hughes JV, Perlow D, Boger J. Induction of hepatitis A virusneutralizing antibody by a virus-specific synthetic peptide. Journal of virology. 1985;55(3):836-9.

.30 Sidney J, Assarsson E, Moore C, Ngo S, Pinilla C, Sette A, et al. Quantitative peptide binding motifs for 19 human and mouse MHC class I molecules derived using positional scanning combinatorial peptide libraries. Immunome research. 2008;4(1):2.

.31 Wang P, Sidney J, Dow C, Mothe B, Sette A, Peters B. A systematic

assessment of MHC class II peptide binding predictions and evaluation of a consensus approach. PLoS computational biology. 2008;4(4):e1000048.

.32 Wang P, Sidney J, Kim Y, Sette A, Lund O, Nielsen M, et al. Peptide binding predictions for HLA DR, DP and DQ molecules. BMC bioinformatics.

2010;11.568:(1)

.33 Bui H-H, Sidney J, Dinh K, Southwood S, Newman MJ, Sette A. Predicting population coverage of T-cell epitope-based diagnostics and vaccines. BMC bioinformatics. 2006;7(1):153.

.34 Nielsen M, Lundegaard C, Lund O, Petersen TN. CPHmodels-3.0-remote homology modeling using structure-guided sequence profiles. Nucleic acids research. 2010;38(suppl_2):W576-W81.

.35 Pettersen EF, Goddard TD, Huang CC, Couch GS, Greenblatt DM, Meng EC, et al. UCSF Chimera - a visualization system for exploratory research and analysis. Journal of computational chemistry. 2004;25(13):1605-12.

.36 Hossain MU, Keya CA, Das KC, Hashem A, Omar TM, Khan MA, et al. An immunopharmacoinformatics approach in development of vaccine and drug candidates for West Nile virus. Frontiers in Chemistry. 2018;6.

.37 Patronov A, Doytchinova I. T-cell epitope vaccine design by immunoinformatics. Open biology. 2013;3(1):120139.

.38 Alberts B, Johnson A, Lewis J, Raff M, Roberts K, Walter P. T cells and MHC proteins. 2002.

.39 Ekins S, Mestres J, Testa B. In silico pharmacology for drug discovery: methods for virtual ligand screening and profiling. British journal of pharmacology. 2007;152(1):9-20. 
$.40 \quad$ Gustiananda M. Immunoinformatics analysis of H5N1 proteome for designing an epitope-derived vaccine and predicting the prevalence of pre-existing cellularmediated immunity toward bird flu virus in Indonesian population. Immunome research. 2011;7(3):1.

.41 Zheng L-N, Lin H, Pawar R, Li Z-X, Li M-H. Mapping IgE binding epitopes of major shrimp (Penaeus monodon) allergen with immunoinformatics tools. Food and Chemical Toxicology. 2011;49(11):2954-60.

.42 Zimic M, Gutiérrez AH, Gilman RH, López C, Quiliano M, Evangelista W, et al. Immunoinformatics prediction of linear epitopes from Taenia solium TSOL18. Bioinformation. 2011;6(7):271.

.43 Kringelum JV, Lundegaard C, Lund O, Nielsen M. Reliable B cell epitope predictions: impacts of method development and improved benchmarking. PLoS computational biology. 2012;8(12):e1002829.

.44 Gaseitsiwe S, Valentini D, Mahdavifar S, Reilly M, Ehrnst A, Maeurer M. Peptide microarray-based identification of Mycobacterium tuberculosis epitope binding to HLA-DRB1* 0101, DRB1* 1501, and DRB1*0401. Clin Vaccine Immunol. 2010;17(1):168-75.

.45 Backert L, Kohlbacher O .Immunoinformatics and epitope prediction in the age of genomic medicine. Genome medicine. 2015;7(1):119. 